\title{
Residence Time Distribution Studies in Continuous Thermal Processing of Liquid Foods: a Review
}

\author{
A. Pinheiro Torres ${ }^{a} \&$ F. A. R. Oliveira ${ }^{b *}$ \\ "Escola Superior de Biotecnologia, R. Dr António Bernardino de Almeida, P-4200 Porto, \\ Portugal \\ 'Instituto Inter-Universitário de Macau, Palácio da Penha, Macau
}

\begin{abstract}
This paper presents a review on residence time distribution (RTD) studies in continuous thermal processing of liquid foods. The theoretical basis of the Danckwerts analysis is summarized, as well as the most important flow models, with special emphasis on tubular systems. Methods for experimental determination, modelling and estimation of RTD are critically described. While main design objectives in continuous thermal processes may be guaranteed by a proper minimum residence or holding time, process optimization requires the knowledge of the residence time distribution. Both concepts are reviewed and discussed. A significant scatter was noticed among published results and the need for a systematic work is clear. It was concluded that future research should focus on studies at pasteurization/sterilization temperatures, as well as on studies conducted with real food products or model food systems with nonNewtonian flow behaviour: Furthermore, information relating RTD to processing conditions would be a useful tool for process optimization. (C) 1998 Elsevier Science Limited. All rights reserved.
\end{abstract}

\section{NOMENCLATURE}

c Concentration, in the time domain $\left(\mathrm{gl}^{-1}\right)$

C Concentration, in the Laplace domain $\left(\mathrm{g} \mathrm{s}^{-1}\right)$

$d \quad$ Tube diameter $(\mathrm{mm}$ or $\mathrm{m})$

D Axial dispersion coefficient $\left(\mathrm{m}^{2} \mathrm{~s}^{-1}\right)$

*To whom correspondence should be addressed. Fax: $+853-725$ 517; e-mail: fernanda( $\alpha$ iium.edu.mo 


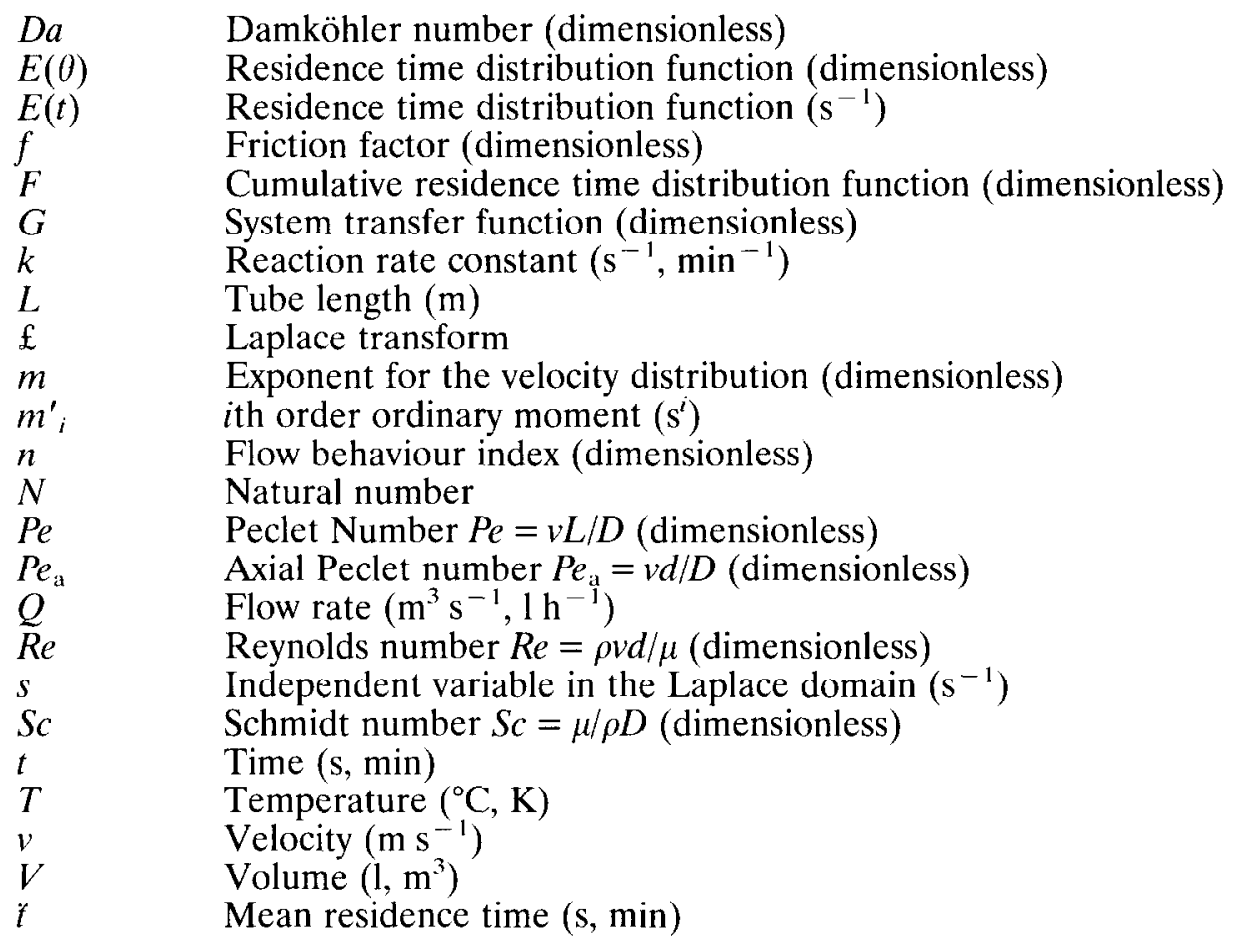

\section{Greek symbols}

$\begin{array}{ll}\alpha, \varphi & \text { Parameters } \\ \beta_{1} & \text { Relative measure of skewness } \\ \beta_{2} & \text { Relative measure of kurtosis } \\ \delta & \text { Dirac function } \\ \varepsilon & \text { Efficiency } \\ \sigma^{2} & \text { Variance }\left(\mathrm{s}^{2}\right) \\ \gamma^{3} & \text { Skewness }\left(\mathrm{s}^{3}\right) \\ \kappa^{4} & \text { Kurtosis }\left(\mathrm{s}^{4}\right) \\ \theta & \text { Dimensionless time } \\ \bar{\theta} & \text { Dimensionless mean residence time } \\ \tau & \text { Mean holding time }(\mathrm{s})\end{array}$

\section{Subscripts}

$\begin{array}{ll}\text { amb } & \text { Ambient } \\ \text { ave } & \text { Average } \\ \mathrm{e} & \text { Output, exit } \\ \mathrm{i} & \text { Input, initial } \\ \text { min } & \text { Minimum } \\ \text { pred } & \text { Predicted }\end{array}$




\section{INTRODUCTION}

Fluid flow can be described by two different approaches: fluid mechanics theory (Taylor, 1954; Brodkey, 1967) or residence time distribution (RTD) theory (Danckwerts, 1953; Zwietering, 1959). Books and chapters have been written on residence time distribution (Levenspiel, 1972; Wen \& Fan, 1975; Hill, 1977; Fromment \& Bischoff, 1979; Fogler, 1986). This concept has been widely applied to chemical processes and more recently has gained a significant interest in the pollution and environmental field, as well as in several biotechnology applications. In general, one can say that RTD analysis is an empirical yet simple approach to describe any process that involves fluid/particulate fluid flow. In the food field, RTD analysis has been applied for assessing the effects of processing parameters on the flow characteristics in different processes, such as extrusion cooking (Yeh et al., 1992; Zulichem et al., 1973) or fermentation processes (Hubbard \& Williams, 1977; Kulozik et al., 1992). In food engineering however, RTD has its widest application in aseptic processing (Bailey \& Ollis, 1986; Burton, 1958a; Rao \& Loncin, 1974a, 1974b; Lin, 1979). Between 1969 and 1994, 165 references were found in the Food Science and Technology Abstracts (FSTA), corresponding to an average of five papers per year, a relatively low number if one considers the impact these studies may have on process assessment and optimization and on diagnosing malfunctions when operating processing equipment (Levenspiel, 1972).

Aseptic processing is commonly applied to a wide range of liquid foods (milk, fruit juices and concentrates, cream, yoghurt, wine, salad dressing, egg and ice cream), foods containing small particles (cottage cheese, baby foods, tomato products, soups and rice desserts) and its application to large particulate foods is currently a major topic of research (Lee et al., 1995; Singh \& Lee, 1992). Systems for the aseptic processing and packaging of fluid foods have been extensively reviewed by Hersom (1985). Continuous aseptic processing involves three major steps: heating. holding and cooling. The food is aseptically processed and then also aseptically packed. Holding temperatures may vary from 65 to $150^{\circ} \mathrm{C}$. Holding times may vary from a few seconds to several minutes and may be attained by choosing an appropriate holding tube length, that is dependent on flow rate.

RTD studies in aseptic processing of foods were first applied to estimate the level of microbial contamination after processing (Bateson, 1971; Burton, 1958b; Burton et al., 1958; Milton \& Zahradnik, 1973; Veerkamp et al., 1974; Wennerberg, 1986). RTD can also be applied to assess mixing between two miscible liquids pumped in succession through a pipe (Sjenitzer, 1958), which is a common procedure in the start-up of aseptic processing units. However, the full potential of RTD studies relies on its applicability to optimization studies. The main advantage of continuous thermal processes when compared to in-container pasteurization or sterilization arises from the quality improvement of the product due to shorter heating and cooling rates (Hersom, 1985). Full potential of continuous thermal processes is yet to be attained and depends on the ability of controlling flow characteristics in processing equipment (Lin, 1979). In continuous thermal processing, time/temperature conditions are constrained by product safety requirements (microorganism or enzymes which may cause degradation or health hazards to be reduced to a target level), while product quality (e.g. texture, colour) should be kept as high as possible. Product safety is related to the minimum residence time (mRT), while product quality relates to the RTD of the product in the system. Optimization of aseptic 
processes may therefore be achieved not only by choosing adequate time/temperature conditions, but also by controlling flow characteristics. RTD theory may also be applied for process optimization in terms of capital and operation costs (Malcata, 1991), though process optimization in terms of product quality is much more important when dealing with food products (Burton, 1958b; Holdsworth \& Richardson, 1986; Kessler, 1989; Lund, 1977; Maesmans et al., 1992; Rao \& Loncin, 1974b).

This paper reviews RTD in continuous thermal processing of liquid foods focusing particularly on the following topics: (i) methods used for experimental measurement of RTD; (ii) methods available for data treatment and analysis; (iii) RTD modelling. One of the most important parameters of RTD in continuous thermal processing is the minimal residence time of the fluid (mRT), as it is directly linked to product safety. Therefore, on this paper mRT and RTD studies will be considered separately, depending whether only $\mathrm{mRT}$ or the whole distribution is considered.

\section{RTD BASIC CONCEPTS}

Flow patterns in continuous systems are usually too complex to be experimentally measured or theoretically predicted from solutions of the Navier-Stokes equation or statistical mechanical considerations (Wen \& Fan, 1975). Real flow systems often deviate from the ideal flow patterns of plug flow (PF), continuous stirred tank (CST) or flow patterns predicted from mechanistic models (Bosworth, 1948, 1949). Real flow systems were first approached by Danckwerts (1953) on the basis of RTD analysis.

The residence time of an element of fluid is defined as the time elapsed from its entry into the system until it reaches the exit. The distribution of these times is called the RTD function of the fluid $E$, or $E$-curve, and represents the fraction of fluid leaving the system at each time, having units of time ${ }^{-1}$ :

$$
E(t)=\frac{c_{\mathrm{e}}(t)}{\int_{0}^{\infty} c_{\mathrm{e}}(t) \mathrm{d} t}
$$

$c_{\mathrm{e}}(t)$ being the exit concentration (e.g. of a tracer) at a certain time $t$.

The mean residence time $t$ is the first moment of the distribution:

$$
\ddot{t} \equiv \int_{0}^{\infty} t \times E(t) \mathrm{d} t
$$

and is equal to the mean holding time $\tau$ for vessels with ideal flow:

$$
\tau=\frac{V}{Q}
$$

with $Q$ standing for product flow rate and $V$ for the system (e.g. the holding tube) volume.

In general, to completely characterize an arbitrary distribution function, all moments are required, but most commonly only moments about the mean up to the fourth level arc considered relcvant. The sccond centred moment, variance $\left(\sigma^{2}\right)$, is an indicator of the spread of the distribution, the third centred moment, called skewness $\left(\gamma^{3}\right)$, is an indicator of the asymmetry of the distribution, and finally, the 
TABLE 1

Centred Moments About the Mean of the RTD Function*

\begin{tabular}{lccc}
\hline Moment & Definition & Formula & Relative measure \\
Variance & $\sigma^{2}=\int_{0}^{\infty}(t-7) 2 \times E(t) \mathrm{d} t$ & $\sigma^{2}=m^{\prime}{ }_{2}-7^{2}$ & $\sigma^{2} /(7)^{2}$ \\
Skewness & $\gamma^{3}=\int_{0}^{\infty}(t-7)^{3} \times E(t) \mathrm{d} t$ & $\gamma^{3}={ }^{3} 3-37 m^{\prime}{ }_{2}+27^{3}$ & $\beta_{1}=\left(\gamma^{3}\right)^{2} /\left(\sigma^{2}\right)^{3}$ \\
Kurtosis & $\kappa^{4} \equiv \int_{0}^{\infty}(t-7)^{4} \times E(t) \mathrm{d} t$ & $\kappa^{4}=m^{\prime}{ }_{4}-47 m^{\prime}{ }_{3}+67^{2} m^{\prime}{ }_{2}-3 t^{4}$ & $\beta_{2}=\kappa^{4} /\left(\sigma^{2}\right)^{2}$ \\
\hline
\end{tabular}

${ }^{*}$ Collected from Hahn and Shapiro (1967).

fourth centred moment, kurtosis $\left(\kappa^{4}\right)$, is an indicator of how heavy-tailed the distribution is (Hahn \& Shapiro, 1967). These centred moments about the mean are defined in Table 1 , and can be easily calculated by using ith order ordinary moments, which are defined as:

$$
m^{\prime}{ }_{i}=\int_{0}^{x} t^{i} \times E(t) \mathrm{d} t
$$

The first ordinary moment of the RTD corresponds to the mean residence time defined in eqn (2).

The F-curve is a cumulative curve which may also be used to characterize the RTD, and corresponds to the fraction of fluid that has spent less than a time $t$ in the system, being therefore defined as:

$$
F(t) \equiv \int_{0}^{1} E(t) \mathrm{d} t
$$

It is often convenient to use a dimensionless time $(\theta$ and the corresponding residence time distribution $E(\theta)$ (Levenspiel, 1972):

$$
\theta=\frac{t}{\tau} \text { and } E(\theta)=\tau \times E(t)
$$

The moments of the RTD curve may also be normalized in the same way (Wen \& Fan, 1975), though the relative measures of the centred moments in Table 1 are more meaningful and are therefore preferred. The centred moments, as well as the $F$-curve, are independent of the time units.

For first order reactions under isothermal conditions, RTD information is sufficient to predict conversion in the system. In this case, the final average concentration, $c_{\text {e.ave }}$, in the exit stream of the system is (Levenspiel \& Bischoff, 1963):

$$
c_{\text {cave }}-\int_{0}^{c_{0}} c_{\mathrm{e}}(t) \times E(t) \mathrm{d} t
$$

where $c_{v}(t)$ is the exit concentration at a certain time $t$. 
For other type of kinetics, the system performance cannot be predicted from RTD and kinetic rate information alone, and the degree of mixing in the system has to be taken into consideration (Zwietering, 1959; Rao \& Loncin, 1974a).

Another concept that can be useful in RTD modelling and data fitting to experimental RTD curves is the transformation of RTD into the Laplace domain. The Laplace transform of a RTD or concentration curve is defined as (Hopkins et al., 1969):

$$
C(s) \equiv f\{c(t)\} \equiv \int_{0}^{\infty} \mathrm{e}^{-s t} c(t) \mathrm{d} t
$$

The system response in the Laplace domain, more commonly called the system transfer function $G(s)$, is for any input function defined as:

$$
G(s) \equiv \frac{C_{\mathrm{e}}(s)}{C_{\mathrm{i}}(s)}
$$

The transfer function for several flow models can be analytically derived from this equation (Hopkins et al., 1969; Wen \& Fan, 1975). Also, the ordinary moments in eqn (4) can be directly obtained for any transfer function of a reactor flow model from the following equation (Wen \& Fan, 1975):

$$
m_{i}^{\prime}=(-1)^{i} \lim _{s \rightarrow 0} \frac{\mathrm{d}^{(i)} G}{\mathrm{~d} s^{(i)}}
$$

this being often a more practical procedure to calculate the centred moments, using the formulae shown in Table 1. It can also be shown that the transfer function $G(s=k)$, for a first order reaction with rate constant $k$, corresponds to the remaining fraction of reactant in the exit stream.

\section{METHODS FOR EXPERIMENTAL DETERMINATION OF RTD CURVES}

\section{Real foods and model fluids}

Model food systems rather than real foods are often used for research purposes, so that problems related to product availability and variability may be overcome. In RTD studies in aseptic processing, model foods should be chosen so that they have rheological and thermal properties similar to those of the food system.

The first mRT experiments on food processes were performed using water as model food (Jordan et al., 1949). Many other authors followed the same approach, although the use of water greatly limits the applicability of the results to a small number of food products and processing conditions (Watson et al., 1960), namely milk, wine and some fruit juices. Only Sancho and Rao (1992) tested other model fluids, such as sucrose and guar gum solutions. In terms of real foods, studies on mRT were reported for milk (Dickerson et al., 1968, 1974; Heppell, 1985; Aoust et al., 1987), milk products (Dickerson et al.), egg products (Kaufman et al., 1968b; Scalzo et al., 1969) and crushed tomato (Rodrigo et al., 1990). Model fluids had a much wider application in RTD determinations; besides water, model fluids tested were: starch solutions (Bateson, 1971), sucrose solutions (Sancho and Rao, 1992), polyethylene glycol (Milton \& Zahradnik, 1973), diethylene glycol (Pudgiono et al., 
1992), glycerol/water mixtures (Trommelen \& Beek, 1971) and guar gum solutions (Sancho \& Rao, 1992). These model fluids cover most rheological behaviour of fluid foods, except for that showing yield stress or very high viscosity. RTD determinations on real products were only reported for milk (Cerf \& Hermier, 1973; Nassauer \& Kessler, 1979; Heppell, 1985; Janssen, 1994), and coffee cream (Kiesner \& Reuter, 1988).

\section{Proposed tracers}

Wen and Fan (1975) summarized the basic requirements for selecting a tracer for RTD experiments: (i) it should be miscible and have physical properties similar to those of the fluid under investigation, (ii) it should be accurately detectable in small amounts, so that its introduction does not affect the flow pattern of the main fluid stream, (iii) its concentration should be easily monitored and the recorded signal should be proportional to tracer concentration, and (iv) sorption of tracer by the vessel walls should not occur.

In mRT determinations, a very low limit of detection is required, because only the first response signal is determinant, as stressed by Jordan et al. (1949), that showed that response accuracy was highly dependent on tracer type and concentration. On the other hand for RTD determinations, accurate detection methods are important, and the response should be preferably proportional to the tracer concentration, so that the analysis can be made directly on the response signal (Wen \& Fan, 1975).

The various tracers proposed for $\mathrm{mRT}$ and RTD experiments in food aseptic processing plants are summarized in Table 2 . It is interesting to note that most tracers proposed for real foods, such as for milk products (Dickerson et al., 1968, 1974; Heppcll, 1985; Patel \& Wilbey, 1990), egg products (Scalzo et al., 1969; Kaufman et al., 1968b) and ice cream mix (Thiel \& Burton, 1952; Botham, 1952), are only suitable for mRT determinations, because of difficulties in tracer detection using real food systems. For the same reason, tracers proposed for whole RTD experiments (soluble dyes, salt, sodium nitrite, labelled microbials and sucrose) were mostly applied to water and model food products, while for real food products only salt was used as tracer in milk (Nassauer \& Kessler, 1979; Heppell, 1985; Janssen, 1994) and coffee cream (Kiesner \& Reuter, 1988). It is however interesting to note that in fields other than aseptic processing, tracers have been applied for RTD measurements in real food systems (e.g. radioactive isotopes in extrusion (Zulichem et al., 1973)).

\section{Tracer injection and detection}

Pcrfcct injections of tracer have the advantage of producing RTD curves that are easy to analyse statistically and mathematically. Common input functions are perfect impulse, step, purge or pulse. Table 3 summarizes these functions in both time and Laplace domain, as well as the corresponding output functions, which are directly related to the $E$ - or $F$-curves.

A perfect impulse of tracer is an ideal concept. Minimal deviations from ideality may be in practice obtained by making the time of injection as short as possible (Aris, 1959). A perfect step is easier to perform than a perfect pulse, but the second method is preferred for commercial testing since the processing system is disturbed 
TABLE 2

Tracers Proposed for Residence Time Experiments in Food Aseptic Processing Plants

\begin{tabular}{|c|c|c|c|c|}
\hline Tracer type & Detection method & Experiment & Application & Reference \\
\hline \multirow[t]{6}{*}{ Soluble dye } & \multirow{4}{*}{$\begin{array}{l}\text { Colorimetry and } \\
\text { photometry }\end{array}$} & \multirow[t]{4}{*}{$\mathrm{mRT}$} & Water & Jordan et al. (1949) \\
\hline & & & Model food & $\begin{array}{l}\text { Pudgiono et al. } \\
\text { (1992) }\end{array}$ \\
\hline & & & Milk products & Heppell (1985) \\
\hline & & & Milk products & $\begin{array}{l}\text { Patel and Wilbey } \\
\text { (1990) }\end{array}$ \\
\hline & \multirow[t]{2}{*}{ Photography } & & Milk & $\begin{array}{l}\text { Dickerson et al. } \\
\text { (1974) }\end{array}$ \\
\hline & & RTD & Water & Roig et al. (1976) \\
\hline \multirow[t]{6}{*}{ Salt } & \multirow[t]{6}{*}{$\begin{array}{l}\text { Electrical } \\
\text { conductivity }\end{array}$} & $\mathrm{mRT}$ & Water & $\begin{array}{l}\text { Jordan et al. (1949); } \\
\text { Anonymous } \\
(1950)\end{array}$ \\
\hline & & \multirow[t]{5}{*}{ RTD } & Water & $\begin{array}{l}\text { Jordan and March } \\
\text { (1953) }\end{array}$ \\
\hline & & & Model foods & $\begin{array}{l}\text { Sancho and Rao } \\
\text { (1992) }\end{array}$ \\
\hline & & & Milk & $\begin{array}{l}\text { Nassauer and } \\
\text { Kessler (1979) }\end{array}$ \\
\hline & & & Coffee cream & $\begin{array}{l}\text { Kiesner and Reuter } \\
\text { (1988) }\end{array}$ \\
\hline & & & Crushed tomato & $\begin{array}{l}\text { Rodrigo et al. } \\
\quad(1990)\end{array}$ \\
\hline Sodium nitrite & $\begin{array}{l}\text { Gries-Ilosvay } \\
\text { reagent }\end{array}$ & $\mathrm{mRT}$ & Ice cream mix & Botham (1952) \\
\hline $\begin{array}{l}\text { Radioactively } \\
\text { labeled } \\
\text { microbials }\end{array}$ & $\begin{array}{l}\text { Gamma } \\
\text { radiation }\end{array}$ & RTD & Water & $\begin{array}{l}\text { Burton et al. (1958) } \\
\text { Aiba and Sonoyama } \\
\quad(1965)\end{array}$ \\
\hline $\begin{array}{l}\text { Radioisotopes } \\
\text { (soluble, } \\
\text { suspended or } \\
\text { entrapped) }\end{array}$ & $\begin{array}{l}\text { Gamma } \\
\text { radiation }\end{array}$ & $\mathrm{mRT}$ & Milk products & $\begin{array}{l}\text { Dickerson et al. } \\
\quad(1968)\end{array}$ \\
\hline \multirow[t]{3}{*}{$\begin{array}{l}\text { Thermal (cold } \\
\text { shot) }\end{array}$} & \multirow[t]{3}{*}{$\begin{array}{l}\text { Temperature } \\
\text { changes }\end{array}$} & \multirow[t]{3}{*}{$\mathrm{mRT}$} & $\begin{array}{l}\text { Egg products } \\
\text { Water }\end{array}$ & $\begin{array}{l}\text { Scalzo et al. (1969) } \\
\text { Jordan and Holland } \\
\quad(1953)\end{array}$ \\
\hline & & & Egg products & $\begin{array}{l}\text { Kaufman et al. } \\
(1968 b)\end{array}$ \\
\hline & & & & $\begin{array}{l}\text { Kaufman et al. } \\
\quad(1968 \mathrm{~b})\end{array}$ \\
\hline $\begin{array}{l}\text { Fluorocarbon } 12 \\
\left(\mathrm{CCl}_{2} \mathrm{~F}_{2}\right)\end{array}$ & $\begin{array}{l}\text { 'Fluor leak } \\
\text { detector' }\end{array}$ & $\mathrm{mRT}$ & Egg products & $\begin{array}{l}\text { Kaufman et al. } \\
\quad(1968 \mathrm{~b})\end{array}$ \\
\hline Sucrose & Polarimetry & RTD & Model foods & $\begin{array}{l}\text { Chen and } \\
\text { Zahradnik (1967) }\end{array}$ \\
\hline
\end{tabular}


TABLE 3

Ideal Forms of Tracer Injection (represented in Time and Laplace Domain), and Corresponding Output Functions

\begin{tabular}{lccc}
\hline Input function & $c_{i}(t)$ & $C_{i}(s)$ & $c_{c}(t)$ \\
\hline Impulse & $c_{\mathrm{i}} \delta(t)$ & $c_{\mathrm{i}}$ & $c_{\mathrm{i}} E(t)$ \\
Step & $c_{\mathrm{i}} U(t)$ & $c_{\mathrm{i}} / s$ & $c_{\mathrm{i}} F(t)$ \\
Purge & $c_{\mathrm{i}}[1-U(t)]$ & $c_{\mathrm{i}}(1-1 / s)$ & $c_{\mathrm{i}}[1-F(t)]$ \\
Pulse & $c_{\mathrm{i}}[U(t)-U(t-a)]$ & $c_{\mathrm{i}}\left\{\left(1-\mathrm{e}^{-a v}\right) / s\right\}$ & $c_{\mathrm{i}}[F(t)-F(t-a)]$ \\
\hline
\end{tabular}

for shorter times (Levenspiel \& Bischoff, 1963). Finally, with respect to the response signal, the step produces an integrated curve which has to be derived to obtain the $E$-curve for data analysis, thus introducing more computational errors or eventually masking some effects, such as tailing. Therefore, the use of step or purge input functions is not as desirable as impulse inputs.

Pulse or step injection of tracer should always be tested to be sufficiently ideal, but this fact is often overlooked in reported works. If the tracer injection is not ideal, special techniques are required for tracer response analysis, and therefore measurement of the injection response is required for performing a non-ideal injection analysis (Aris, 1959).

Various experimental methods for tracer injection and detection have been developed and optimized and are well described in literature (Anonymous, 1950; Burton, 1958a; Edgerton \& Jones, 1970; Jordan \& Holland, 1953; Jordan et al., 1949; O'Callaghan \& McKenna, 1974). Some studies were made specifically on tracers for real foods, as can be seen in Table 2. Except for Burton (1958a, 1958b) and Burton et al. (1977), who analysed respectively the importance of satisfactory injection and detection conditions on the RTD response, all tracer injection methods were developed for $\mathrm{mRT}$ determinations.

Both Aiba and Sonoyama (1965) and Roig et al. (1976) used step injections and obtained RTD curves corresponding to the $F$-curve. Other researchers used impulse injections, but none reported having checked the ideality of injection, except for Sancho and Rao (1992). Only Kiesner and Reuter (1988, 1990) reported non-ideal injections, and analysed their data accordingly.

\section{MODELS FOR FLOW IN TUBULAR SYSTEMS}

\section{mRT models}

Although some authors advise experimental determination of mRT (Jordan et al., 1949; Anonymous, 1950), others propose conservative models for estimating mRT from mean holding times $\tau$ (eqn (3)) in holding tubes (Table 4). The efficiency of a hold tube, $\varepsilon$, can be defined by the following equation (Rao \& Loncin, 1974a):

$$
\varepsilon(\%)=\frac{m R T}{\tau} \times 100 \% \text { or } \varepsilon=\frac{m R T}{\tau}
$$




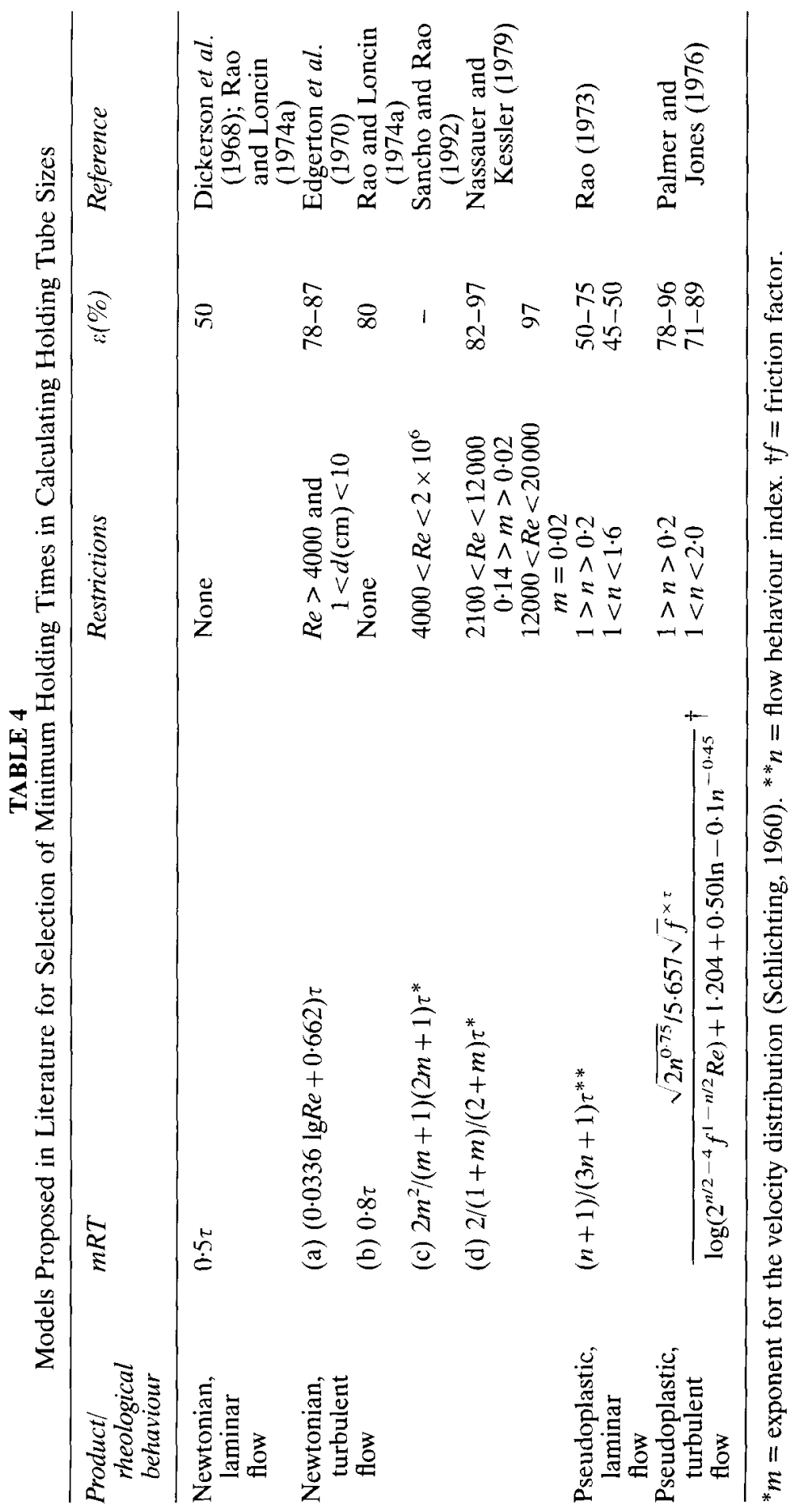


and is never below $50 \%$ for Newtonian fluids in laminar flow (Table 4). Efficiency below $50 \%$ can only occur for dilatant fluids (with flow behaviour index $n<1$ ) in laminar flow (Rao, 1973). In turbulent flow, the theoretical efficiency is always above $70 \%$ for any model fluid, as shown in Table 4 . There is a lack of models for predicting efficiencies in the transition flow regime zone $(2100<R e<4000)$, as can be concluded from the analysis of Table 4.

The prediction of velocity profiles for fluids in turbulent flow is not as straightforward as for laminar flow. For Newtonian fluids, relationships are reliable, but the available equations for power law fluids have not received adequate experimental verification for food materials (Steffe, 1992). Therefore, models proposed for mRT and efficiency calculations for fluids other than Newtonian are less reliable, as they are mostly derived from the above-mentioned relationships. However, these predictive models tend to be conservative, as they are mostly based on ideal flow conditions. Non-ideal flow, due mostly to bends in tubes, entrance and end effects which do not allow fully developed flow conditions, leads to more turbulence and an mRT consequently higher than that expected from theoretical considerations and corresponding tube efficiency.

\section{Influence of boundary conditions on flow modelling}

The procedure used in RTD experiments may determine the resultant tracer output curve. Levenspiel and Turner (1970) illustrated experimentally the effect of injection and measurement of tracer on the shape, mean and spread of the resultant tracer curve. Two possible tracer inputs were considered, namely proportional to the velocity of flow (referred as open boundary condition) or evenly across the flowing strcam (referred as closed boundary condition); tracer was measurcd by either the mixing-cup technique or by a through the wall measurement. Levenspiel et al. (1970) related the tracer curves obtained by these various techniques, for situations where interaction between neighbouring streamlines is negligible. The features of the main boundary conditions are discussed by Wen and Fan (1975).

\section{RTD models commonly applied for tube flow}

Theoretical models for fluid flow in tubular systems (as holding tubes) at isothermal conditions are summarized in Table 5. These models were divided in mechanistic (derived from fluid mechanics theory) or stochastic (based on probability theory) models.

Ideal RTD models like the plug flow (PF) and ideal continuous stirred tank (CST) rarely reflect a real situation with enough accuracy. Non-ideal models are usually built from ideal models, accounting for deviations from real systems, and can be divided into single and multiparameter models. These models vary in complexity and one parameter model is often adequate to represent tubular systems (Levenspiel \& Bischoff, 1963). The most common models describing tube flow are summarized in Table 6, where the corresponding RTD, transfer functions and relative moments are presented.

The axial dispersed plug fluw model, or simply the dispersion model, is probably the most widely applied to describe flow in tubes, and thus often applied to simulate product flow in holding tubes. This model considers that axial diffusion is super- 
imposed to plug flow, and the resulting axial dispersion, $D$, is expressed in a dimensionless Peclet number, $P e$ :

$$
P e=\frac{v L}{D}
$$

where $L$ is the length of the tube and $v$ is the average velocity in the tube. This dimensionless parameter may also be called Bodenstein number (Holdsworth, 1970). Expressions for the axial dispersion model and for estimating the corresponding characteristic parameter $(\mathrm{Pe})$ for the various combinations of boundary conditions and input functions were first derived by Aris (1959), Bischoff (1960), Bischoff and Levenspiel (1962a) and Laan (1958). Results were compared by Bischoff and Levenspiel (1962a, 1962b) for various conditions.

For small extents of dispersion, or large $P e$ numbers $(P e \geq 500)$, this model does not depend on the boundary conditions, whereas for small values of $P e$ it depends on the type of boundary conditions imposed. The analytical solution for open vessels

TABLE 5

Theoretical Models in I iterature for Fluid Flow in Pipes

\begin{tabular}{|c|c|c|c|}
\hline Model & Rheological behaviour & Mixing conditions & Reference \\
\hline \multirow[t]{7}{*}{ Mechanistic } & \multirow{2}{*}{$\begin{array}{l}\text { Laminar flow, } \\
\text { Newtonian fluid }\end{array}$} & Without diffusion & Bosworth (1948) \\
\hline & & $\begin{array}{l}\text { With radial or } \\
\text { longitudinal } \\
\text { diffusion in helical } \\
\text { tube }\end{array}$ & Bosworth (1948) \\
\hline & Laminar flow, power- & & $\begin{array}{l}\text { Ruthven (1971) } \\
\text { Lin (1980) }\end{array}$ \\
\hline & $\begin{array}{l}\text { Laminar flow, } \\
\text { Bingham-plastic } \\
\text { fluid }\end{array}$ & & $\begin{array}{l}\text { Guariguata et al. } \\
\text { (1979) }\end{array}$ \\
\hline & $\begin{array}{l}\text { Laminar flow, Prandtl- } \\
\text { Eyring fluid }\end{array}$ & & $\begin{array}{l}\text { Sawinsky and Simand } \\
\text { (1982) }\end{array}$ \\
\hline & $\begin{array}{l}\text { Turbulent flow, } \\
\text { Newtonian fluid }\end{array}$ & Without diffusion & Bosworth (1949) \\
\hline & & $\begin{array}{l}\text { With radial or } \\
\text { longitudinal } \\
\text { diffusion }\end{array}$ & Bosworth (1949) \\
\hline \multirow{2}{*}{$\begin{array}{l}\text { Stochastic, single } \\
\text { parameter }\end{array}$} & & Axial dispersion model & Danckwerts (1953) \\
\hline & & Tanks-in-series model & $\begin{array}{l}\text { Buffham and Gibilaro } \\
(1968)\end{array}$ \\
\hline \multirow{2}{*}{$\begin{array}{l}\text { Stochastic, } \\
\text { multiparameter }\end{array}$} & & Dispersion models & Wen and Fan (1975) \\
\hline & & Combined models & $\begin{array}{l}\text { Levenspiel and } \\
\text { Bischoff (1963) }\end{array}$ \\
\hline
\end{tabular}




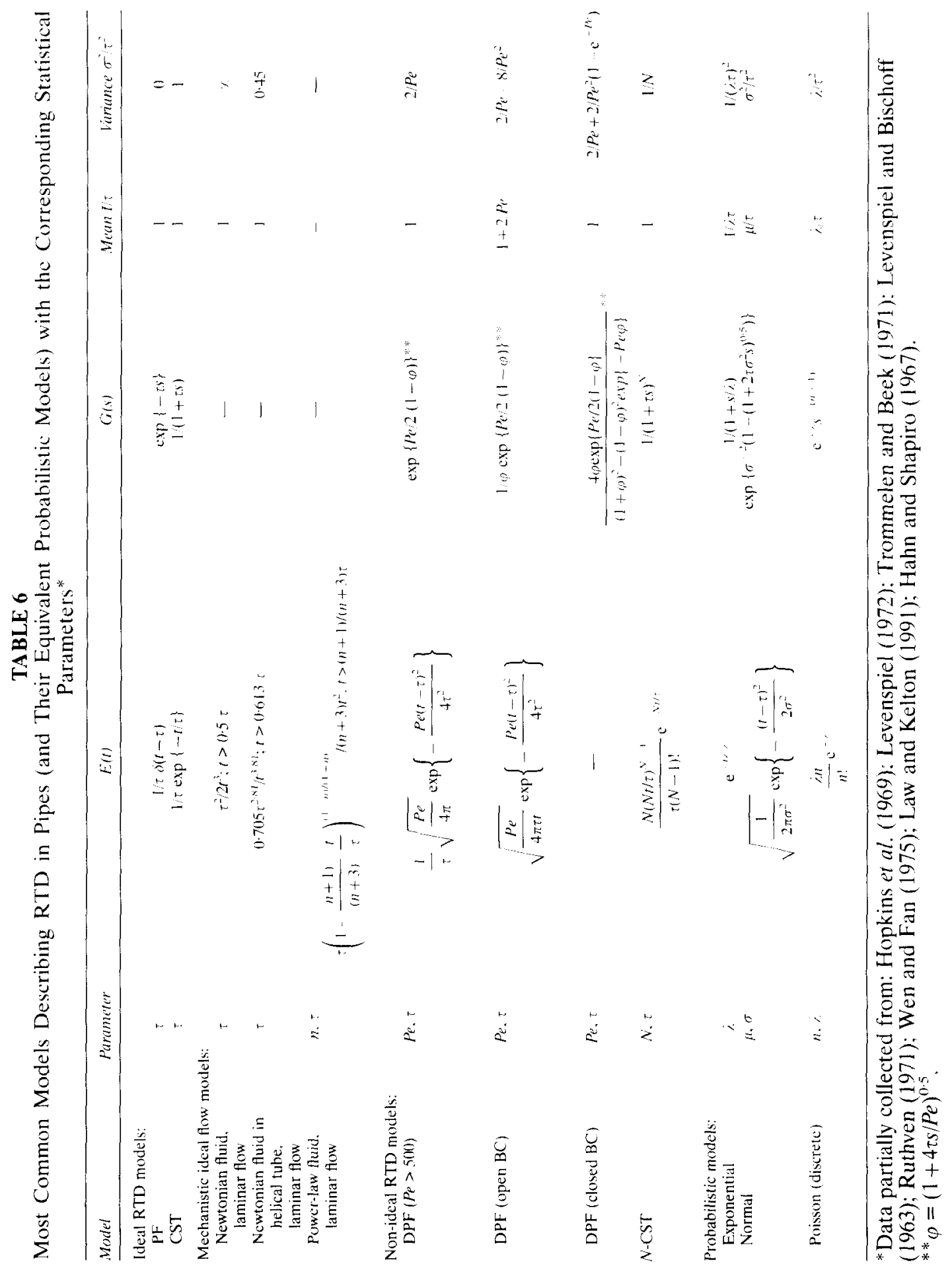




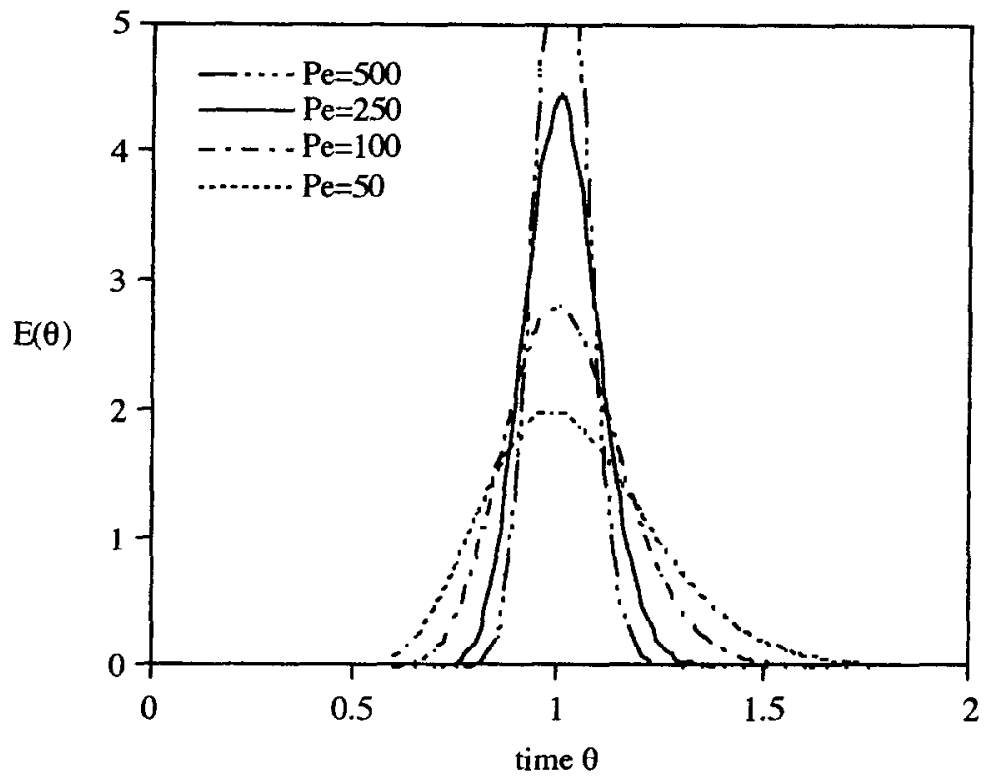

Fig. 1. E-curves for different Peclet numbers, using the dispersion model.

is shown in Table 6 and the corresponding RTD curves are represented in Fig. 1, for different $P e$ numbers.

Wehner and Wilhelm (1956) solved analytically the differential equation resulting from a mass balance to a reactant in an axially dispersed plug flow reactor, which follows a first order kinetics, and obtained an expression for the final concentration as function of the kinetic rate parameter for the reaction and the $P e$ number (Levenspiel, 1972). This equation is valid for any kind of boundary conditions and can be rewritten as function of dimensionless numbers $P e$ and $D a$ :

$$
\left(\frac{c_{\mathrm{e}}}{c_{\mathrm{i}}}\right)=f(P e, D a)=\frac{4 \alpha \mathrm{e}^{P e / 2}}{(1+\alpha)^{2} \mathrm{e}^{\alpha P_{e} / 2}-(1-\alpha)^{2} \mathrm{e}-{ }^{\alpha P e / 2}}
$$

with:

$$
\alpha=\sqrt{1+4 D a / P e}
$$

where the Damköhler number, $D a$, is a dimensionless form of expressing the reaction rate constant, $k$ :

$$
D a=k \times \tau
$$

The $N$-CST model has also been applied to describe flow in tubes (Levenspiel \& Bischoff, 1963; Wen \& Fan, 1975) and in aseptic processes (Veerkamp et al., 1974; Roig et al., 1976; Wennerberg, 1986; Malcata, 1991; Sancho \& Rao, 1992). 
It is interesting to note that some stochastic non-ideal RTD models (single CST, DPF for large $P e$ and the $N$-CST) are equivalent to classical probabilistic models (exponential, normal and Poison distribution, respectively). These are also represented in Table 6 for comparison.

\section{Relating RTD parameters with product properties and processing conditions}

Several correlations relating $P e$ to the Reynolds number $(R e)$ were found in literature for Newtonian fluids in tube flow (Table 7). One should note that those correlations are usually based on the axial Peclet number, $P e_{\mathfrak{a}}$, which is related to the diameter and not the length of the tubular system:

$$
P e_{\mathrm{a}}=P e \times \frac{d}{L}=\frac{v d}{D}
$$

No correlations were found for the transient regime. In laminar flow, the relation between $\mathrm{Pe}$ and $R e$ is also dependent on the Schmidt $(S c)$ number that relates hydrodynamic with diffusional mass transfer.

TABLE 7

Empirical Correlations Between RTD and Processing Parameters

\begin{tabular}{lcc}
\hline Reference & Correlation & Restrictions \\
\hline Levenspiel (1958) & $\frac{1}{P e_{\mathrm{a}}}=\frac{\operatorname{Re} \times S c}{192}$ & $R e<2100$ \\
Wen and Fan (1975) & $\frac{1}{P e_{\mathrm{a}}}=\frac{1}{R e \times S c}+\frac{R e \times S c}{192}$ & $R e<2000$
\end{tabular}

$$
\text { Turbulent flow: } 1 / P e_{\mathrm{it}}=f(R e, L / d)
$$

Taylor (1954)

$$
\frac{1}{P e_{\mathrm{a}}}=\frac{2 \cdot 010}{\operatorname{Re}^{0.125}} *
$$

Nassauer and Kessler (1979)

$$
\frac{1}{P e_{\mathrm{a}}}=\frac{0.766}{R e^{0.1}}
$$

Sjenitzer (1958)

$$
\frac{1}{P e_{\mathrm{a}}}=\frac{1429}{R e^{(0.9}}\left(\frac{L}{d}\right)^{0.141} *
$$

$\operatorname{Re}>3000$

Wen and Fan (1975)

$$
\frac{1}{P e_{\mathrm{a}}}=\frac{3.0 \times 10^{7}}{R e^{2.1}}+\frac{1.35}{R e^{0.125}} \quad R e>3000
$$

\footnotetext{
*Altered using the Blasius equation, which relates the friction factor to the Re number (Bird et al., 1960) for $3000<R e<100000$ and smooth pipes.
} 


\section{Estimation of parameters from experimental data}

A full analysis of RTD curves requires an appropriate raw data treatment and the subsequent fitting of models to experimental data. Various methods can be applied to obtain the characteristic parameters of the RTD models and the techniques available for parameter estimation can be divided in time or Laplace domain analysis. The first is the most commonly adopted, either by using analysis of given characteristics of the RTD curve, moments analysis or curve fitting by non-linear optimization. Frequency domain curve fitting has also been described, although rarely used in aseptic processing. Advantages and inconveniences of these methods are summarized in Table 8. Some of the above mentioned methods allow the analysis of RTD curves obtained from non-ideal input functions.

\section{Treatment of raw data of RTD curves}

RTD curves may be obtained simply from normalization of output concentration curves to a Dirac input, according to eqn (1). The mean residence time (eqn (2)) can be directly calculated, as well as the variance, skewness and kurtosis (Table 1). To evaluate the integrals for moments calculation, the integration has to be done up to some finite time, and Aris (1959) reported that in order to guarantee an error lower that $1 \%$ in the estimates, integration should be conducted up to a time period equivalent to three times the mean residence time. If the first moment equals the mean holding time $\tau$, the RTD curves can be readily normalized with respect to time (eqn (6)); otherwise this parameter is preferably estimated together with the model curve parameters (Fahim \& Wakao, 1982). As evaluation of moments is very influenced by data errors (noise, premature truncation of response or tailing of RTD curves), normalization of the RTD curves should be cautiously applied.

Tailing of RTD curves is commonly observed and several models have been put forward to explain this anomaly (Levenspiel, 1972). These models may be rather complex and with regard to application of RTD in the estimation of reactants' conversion, the tail correction usually does not justify the extra modelling work (Levenspiel, 1972). On the other hand, the tailing assumes an important role in the accurate estimation of the model parameters, even in terms of the computation of the moments of RTD curve. Several solutions have been proposed in literature for overcoming this problem: (i) truncation of the output curve and approximation of the tail after the truncation point to an exponential decay (Wen \& Fan, 1975); (ii) estimation of parameters from other sections of the RTD curve (Levenspiel, 1972); (iii) empirical corrections of RTD curves (Wen \& Fan, 1975); and (iv) use of Laplace transform techniques which allow for linearization of the RTD curve (Østergaard \& Michelsen, 1969; Hopkins et al., 1969).

\section{Time domain curve analysis}

The most simplc and rapid method for parameter estimation in the time domain consists in analysing specific characteristics of the RTD curve (A1 in Table 8) such as the peak time and height, inflection points or defined areas under the RTD curve. For example, $\mathrm{Pe}$ in the dispersion model can be estimated from the peak height of the $E$-curve, or $N$ in the $N$-CST model can be estimated from the peak time (Levenspiel, 1972). Model parameters estimated in this way may not be very 


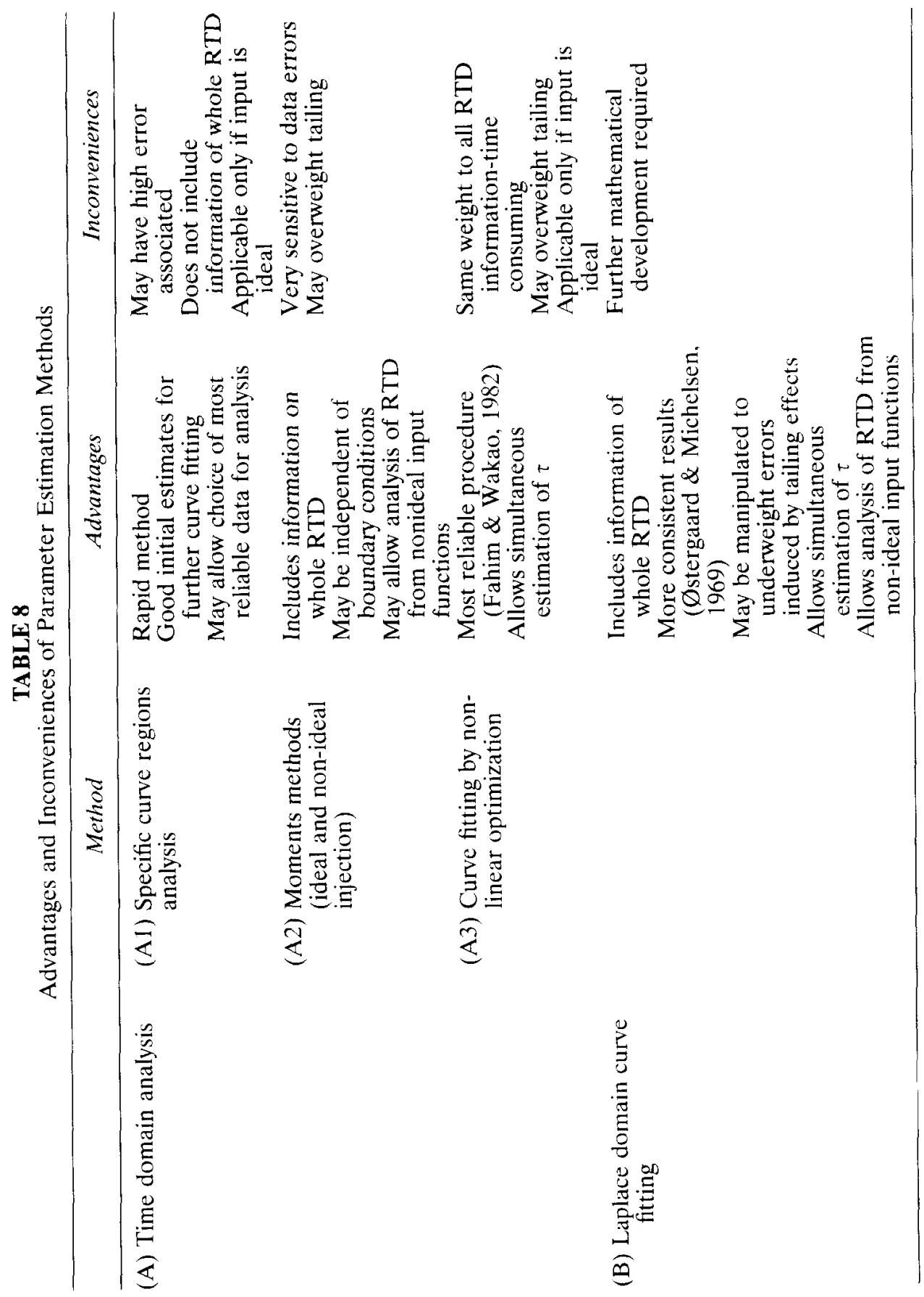


accurate, but provide good initial estimates for further time domain curve fitting (Fahim \& Wakao, 1982).

The moments of tracer curves (A2 in Table 8) may also be used to estimate directly the parameters of some simple models, such as the dispersion model for different boundary conditions (Levenspiel \& Smith, 1957; Pethö, 1968), in case of ideal tracer injection. For cases where the input tracer function is not ideal, Aris (1959) proposed a method for estimating dispersion numbers from moments analysis for both injection and response curves for open vessels. This method, corrected by Bischoff (1960), was extended to other experimental schemes with different boundary conditions applied to the dispersion model by Bischoff and Levenspiel (1962a), and is also described by Wen and Fan (1975). It consists in calculating Pe from the difference of variances of both input and output RTD responses, where

$$
\Delta \sigma^{2}=\sigma_{\mathrm{e}}^{2}-\sigma_{\mathrm{i}}^{2}=2 / P e
$$

Levenspiel and Bischoff (1963) summarized the main advantages of this method for nonideal input functions: (i) it does not require any specific distribution of the input; (ii) it does not depend on the boundary conditions; (iii) it uses the information contained in the whole RTD curve, not only specific characteristics. The main drawback is that the estimated moments are greatly dependent on the tail end of the recorded curve, and therefore slight errors at higher times may be strongly magnified.

Time-domain curve fitting by non-linear optimization (A3 in Table 8) is considered the most reliable procedure (Fahim \& Wakao, 1982). The model parameters may be estimated by non-linear optimization techniques, although problems may arise when estimating simultaneously more than one parameter, particularly if they are highly correlated. Furthermore, mean residence time can be estimated along with the model paramctcrs (Rangaiah \& Krishnaswamy, 1990).

\section{Laplace domain curve fitting}

Other methods applicable to data processing of non-ideal pulse responses have been proposed (Wen \& Fan, 1975). These methods (B in Table 8) use the system transfer function $G(s)$ in eqn (9), calculated from the experimental RTD curve. Results are obtained directly from curve fit in the $s$-domain using the models' transfer functions (Hopkins et al., 1969; Østergaard \& Michelsen, 1969) or from a modified moments analysis in the Laplace domain (Østergaard \& Michelsen, 1969).

The range of $s$ values which gives least error in the predicted model parameters has to be evaluated case by case and may eliminate tailing effects in results (Hopkins et al., 1969). Østergaard * Michelsen (1969) estimated Pe numbers for the dispersed plug flow model from both the moments method in the time domain and by the transfer function (performing a linearization in the Laplace domain for parameters estimation), and found the latter to give more consistent results and to be rather insensitive to the duration of the recording period, in contrast to the moments analysis. They also introduced a modified moments analysis in the Laplacc domain, which was the only method of nonideal input function analysis applied to RTD in an aseptic processing system (Kiesner and Reuter, 1988, 1990). 


\section{EXPERIMENTAL AND MODELLING STUDIES}

\section{Minimum holding times}

Earlier studies were conducted to check the correct sizing of hold tubes in industrial equipment. The theory of residence times was first adopted for determining sterilization efficiency (eqn (11)) in holding tubes. This was incipiently done by Jordan et al. (1949), Jordan and March (1953) and Jordan and Holland (1953) in holding tubes, although their work was largely ignored by other researchers at that time (Lin, 1979). This kind of studies was later applied in the late 1960s on commercial equipment, as can be seen in Table 9. The main application of these studies was to check the correct sizing of hold tubes in industrial equipment.

Table 9 summarizes the experimental methods and operating conditions for each case studied, including experimental efficiency values. When these values were not reported, we have estimated them from reported values of minimum and average holding time. Table 9 also includes efficiency values predicted using the adequate models presented in Table 4 . In the cases where reported data was insufficient to describe the fluid rheological behaviour, we considered the conservative case of Newtonian fluids, as proposed by Dickerson et al. (1968) and Scalzo et al. (1969). It was found that experimental efficiencies are in general greater than those predicted, which may be due to three main reasons: (i) nonideality of the flow - this may be significant in situations where laminar flow is not fully developed, or when the fluid is flowing through bent pipes, so that streamlines are broken, inducing a higher mixing of fluid, less spread of residence times and higher mRT; (ii) sensitivity of the tracer detection method - the higher the tracer quantity required for detection, the lower the efficiency value experimentally determined (Jordan et al., 1949; Jordan \& Holland, 1953); and (iii) errors in the calculation of the mean residence time. The only exception, where predicted efficiencies were greater than those measured experimentally, was found for some egg products in the transition flow regime (Kaufman et al., 1968a), but in this study Re numbers were calculated assuming Newtonian flow behaviour, not taking into consideration that many egg products may show a pseudoplastic flow behaviour and/or yield stress (Holdsworth, 1971; Rao, 1977; Steffe, 1992). This comment is also valid for the work of Dickerson et al. (1968) who studied some milk products (condensed skim milk, cream with $40 \%$ fat) and for the work of Rodrigo et al. (1990) on crushed tomato. Relative deviations between experimental and predicted efficiencies for most Newtonian fluids (water and some milk products), were found to be positive and relatively low, while dependant on flow regime $(<2.4 \%$ for turbulent, $<5 \%$ for transient and $<22 \%$ for laminar flow). On the other hand, relative deviations for egg products showing Newtonian flow behaviour (up to 52\%), reported by Kaufman et al. (1968a) and Scalzo et al. (1969), were much larger, suggesting that the tracers used in cgg products may have a quite different detection level.

In many situations, efficiencies are experimentally assessed by the standard salt conductivity test performed on water, at processing conditions (holding time and temperature) identical to those the real food product will be subjected to. It is therefore most important to assess the validity of such procedure. We have calculated relative deviations between experimental efficiencies of water and other food products from published data (Table 10). Deviations up to 3\% (Sancho \& Rao, 1992) and 7\% (Dickerson et al., 1968) were found for Newtonian fluids, indepen- 


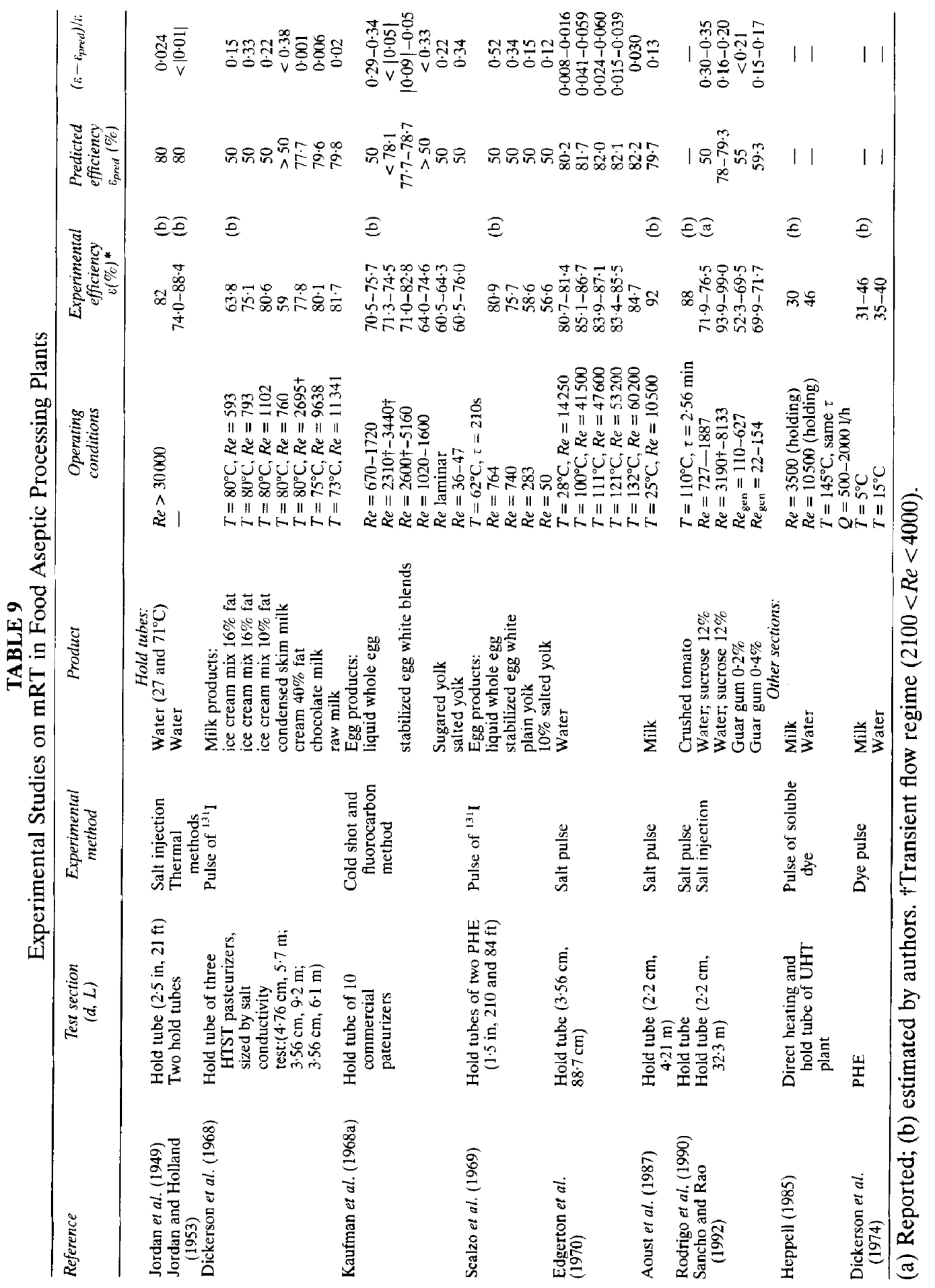


TABLE 10

Comparison Between Experimental Efficiencies for Water and Food Products

\begin{tabular}{|c|c|c|c|c|}
\hline Reference & Food product & $\begin{array}{c}\text { Eprodiuct } \\
(\%)\end{array}$ & $\begin{array}{c}E_{\text {water }} \\
(\%)\end{array}$ & 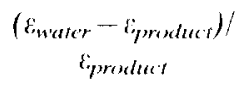 \\
\hline \multirow{7}{*}{$\begin{array}{l}\text { Dickerson et al. } \\
\quad(1968)\end{array}$} & Milk products: & & & \\
\hline & condensed skim milk & 59 & $87 \cdot 8$ & $0 \cdot 33$ \\
\hline & ice cream mix 1 & $75 \cdot 1$ & $90 \cdot 1$ & $0 \cdot 17$ \\
\hline & ice cream mix 2 & $80 \cdot 6$ & $90 \cdot 1$ & $0 \cdot 11$ \\
\hline & cream & $77 \cdot 8$ & $90 \cdot 1$ & () 14 \\
\hline & chocolate milk & $80 \cdot 1$ & $85 \cdot 8$ & 0.07 \\
\hline & raw milk & $81 \cdot 7$ & $85 \cdot 8$ & $0 \cdot 05$ \\
\hline \multirow{2}{*}{$\begin{array}{l}\text { Sancho and Rao } \\
\text { (1992) }\end{array}$} & Sucrose $12 \%$ (laminar) & $72 \cdot 2-76 \cdot 5$ & $74-74 \cdot 3$ & $<|0.03|$ \\
\hline & Sucrose $12 \%$ (turbulent) & $93 \cdot 5-99$ & $93-96 \cdot 4$ & $<|0 \cdot 03|$ \\
\hline
\end{tabular}

dently of the flow regime. Non-Newtonian fluids show much higher deviations, as would be expected, reaching values as high as 33\%. Dickerson et al. (1968) found that the standard salt conductivity test was satisfactory for milk and chocolate milk, whereas errors up to $33 \%$ were found for more viscous milk products. Heppell (1985) also compared mRT values obtained for water and for milk processed in a heat and a holding section of a UHT plant, for three different holding temperatures. To maintain the same temperature and mean residence time, for water and milk, different flow rates and thus different $R e$ numbers were however used for each fluid, thus preventing a true comparison from being made. Similarly, Dickerson et al. (1974) compared efficiencies for milk and water in a PHE, but using different processing temperatures for each product.

In general terms, it should be stressed that there are various sources of errors that should be carefully taken into consideration when determining both mRT and efficiency values in continuous processing systems. The models proposed in Table 4 appear to be conservative when applied for hold tube sizing, thus guaranteeing the product safety, except for products flowing in the transition zone $(2100<\operatorname{Re}<4000)$. The classical test of salt conductivity in water yields good results for Newtonian fluids, but is quite conservative when applied for non-Newtonian fluids.

\section{Residence time distributions}

Table 11 summarizes reported experimental studies on RTD in holding tubes of food aseptic processing plants. Similar information for heat transfer sections (heating and cooling) can be found in Table 12. Most studies were conducted with water and salt was preferred as tracer. Model food products tested include sucrose and guar gum solutions (Sancho \& Rao, 1992), diethylene glycol (Pudgiono et al., 1992), polyethylene glycol (Milton \& Zahradnik, 1973), glycerol-water mixtures (Trommelen \& Beek, 1971) and starch (Bateson, 1971). RTD studies on real products were performed with milk (Cerf \& Hermier, 1973; Nassauer \& Kessler, 1979; Heppell, 1985; Janssen, 1994) and coffee cream (Kiesner \& Reuter, 1988).

The first RTD studies in holding tubes (Table 11) were performed by Jordan and March (1953) and Dickerson et al. (1968), to assess overholding times (holding 
times expressed in a shifted time scale where mRT is taken as time zero) and their dependence on processing conditions. One can find studies on a large diversity of holding tubes sizes although a limited number of processing conditions was tested for each. Jordan and March (1953), Burton (1958a), Chen and Zahradnik (1967), Milton and Zahradnik (1973), Burton et al. (1977) and Janssen (1994) were the only authors that tested RTD in holding tubes at temperatures above ambient. Studies

TABLE 11

Experimental Studies on RTD in Food Aseptic Processing Plants - Hold or Straight Tubes

\begin{tabular}{|c|c|c|c|c|c|}
\hline Reference & $\begin{array}{l}\text { Test section } \\
\quad(d, L)\end{array}$ & Method & Product & $\begin{array}{l}\text { No. of } \\
\text { runs }\end{array}$ & $\begin{array}{l}\text { Operating } \\
\text { conditions }\end{array}$ \\
\hline $\begin{array}{l}\text { Jordan and } \\
\text { March } \\
(1953)\end{array}$ & $\begin{array}{l}\text { Hold tubes }(1-2 \cdot 5 \\
\text { in; } 9-53 \mathrm{ft})\end{array}$ & Salt pulse & Water & 9 & $\begin{array}{c}R e=7500-50000 \\
T=71^{\circ} \mathrm{C}\end{array}$ \\
\hline $\begin{array}{l}\text { Burton } \\
\quad(1958 \mathrm{a})\end{array}$ & Hold tube of PHE & $\begin{array}{l}\text { Sodium } \\
\text { nitrite }\end{array}$ & Water & 1 & $\begin{array}{r}R e=25000 \\
T=135^{\circ} \mathrm{C}\end{array}$ \\
\hline $\begin{array}{l}\text { Aiba and } \\
\text { Sonoyama } \\
(1965)\end{array}$ & $\begin{array}{l}\text { Straight tubes } \\
\quad \begin{array}{l}(3.9 \mathrm{~mm}, \\
2 \cdot 37+11 \mathrm{~m})\end{array}\end{array}$ & $\begin{array}{l}\text { Step of }{ }^{32} \mathrm{P} \\
\text { marked } \\
\text { microbial } \\
\text { suspension }\end{array}$ & Water & $2+1$ & $\begin{array}{l}R e=420 \text { and } 2260 \\
\quad T_{\text {amb }}\end{array}$ \\
\hline $\begin{array}{l}\text { Chen and } \\
\text { Zahradnik } \\
(1967)\end{array}$ & Hold tube of SSHE & Sucrose pulse & Water & 3 & $\begin{array}{c}\text { Three flowrates, } \\
T=87^{\circ} \mathrm{C}\end{array}$ \\
\hline $\begin{array}{l}\text { Milton and } \\
\text { Zahradnik } \\
\text { (1973) }\end{array}$ & Hold tube of SSHE & Sucrose pulse & $\mathrm{PEG}^{*} 25 \%$ & 2 & $\begin{array}{c}\text { Two flowrates, } \\
T=124^{\circ} \mathrm{C}\end{array}$ \\
\hline $\begin{array}{l}\text { Veerkamp } \\
\text { et al. } \\
\text { (1974) }\end{array}$ & $\begin{array}{l}\text { Two hold tubes, } \\
\text { same } \tau(8 \mathrm{~cm} \text {, } \\
1.5 \mathrm{~m})(1.35 \mathrm{~cm} \text {, } \\
52.5 \mathrm{~m})\end{array}$ & Salt pulse & Water & 2 & $\begin{array}{c}T_{\mathrm{amb},} \tau=140 \mathrm{~s}, \\
\operatorname{Re}=860 \\
\operatorname{Re}=5100\end{array}$ \\
\hline $\begin{array}{l}\text { Roig et al. } \\
\quad(1976)\end{array}$ & Two hold tubes & $\begin{array}{l}\text { Dye step and } \\
\text { purge }\end{array}$ & Water & 2 & $\begin{array}{l}\text { Two flowrates, } \\
\begin{array}{l}T=26 \cdot 7^{\circ} \mathrm{C} \\
\tau=9-13 \cdot 3 \mathrm{~s}\end{array}\end{array}$ \\
\hline $\begin{array}{l}\text { Burton et al. } \\
\text { (1977) }\end{array}$ & Hold tube & Salt pulse & Water & $1+5$ & $\begin{array}{l}R e>5000 \\
\quad T=130-150^{\circ} \mathrm{C}\end{array}$ \\
\hline $\begin{array}{l}\text { Nassauer and } \\
\text { Kessler } \\
(1979)\end{array}$ & $(<25 \mathrm{~mm},<52 \mathrm{~m})$ & Salt step & Water & 1 & $R e=5000$ \\
\hline $\begin{array}{l}\text { Wennerberg } \\
\text { (1986) }\end{array}$ & $\begin{array}{r}(35.6 \mathrm{~mm}, 43 \cdot 3 \mathrm{~m}) \\
(65 \mathrm{~mm}, 15 \cdot 3 \mathrm{~m})\end{array}$ & Salt pulse & $\begin{array}{c}\text { Milk } \\
\text { Water }\end{array}$ & $\begin{array}{l}1 \\
2\end{array}$ & $\begin{array}{l}R e=5820 ; T_{\mathrm{amb}} \\
\operatorname{Re}=21400,35300 ; \\
\quad T_{\mathrm{amb}}\end{array}$ \\
\hline $\begin{array}{l}\text { Kiesner and } \\
\text { Reuter } \\
(1990)\end{array}$ & $(5.0 \mathrm{~cm} ; 1.05 \mathrm{~m})$ & Salt pulse & Water & 12 & $R e=20000-100000$ \\
\hline \multirow[t]{2}{*}{$\begin{array}{l}\text { Sancho and } \\
\text { Rao (1992) }\end{array}$} & $(2 \cdot 22 \mathrm{~cm}, 32.3 \mathrm{~m})$ & Salt pulse & Water & 10 & $\operatorname{Re}=800-8133$ \\
\hline & & & $\begin{array}{c}\text { Sucrose } 12 \% \\
\text { Guar } 0.2 \text { and } \\
0.4 \%\end{array}$ & $\begin{array}{c}10 \\
7+5\end{array}$ & $\begin{array}{l}R e=727-6071 \\
\operatorname{Re}_{\text {gen }}=22-627\end{array}$ \\
\hline $\begin{array}{l}\text { Janssen } \\
\quad(1994)\end{array}$ & Hold tube $(\tau=70 \mathrm{~s})$ & Salt & Milk & 1 & $\begin{array}{l}T=25^{\circ} \mathrm{C} \\
T=90^{\circ} \mathrm{C}\end{array}$ \\
\hline
\end{tabular}

*Polyethylene glycol. 
TABLE 12

Experimental Studies on RTD in Food Aseptic Processing Plants-Heating and/or Cooling Sections

\begin{tabular}{|c|c|c|c|c|c|}
\hline Reference & Test section & Method & Product & $\begin{array}{l}\text { No. of } \\
\text { runs }\end{array}$ & $\begin{array}{l}\text { Operating } \\
\text { conditions }\end{array}$ \\
\hline \multicolumn{6}{|l|}{ PHEs } \\
\hline $\begin{array}{l}\text { Watson et al. } \\
\qquad(1960)\end{array}$ & 3 PHE & Salt and dye step & Water & - & - \\
\hline $\begin{array}{l}\text { Wennerberg } \\
\text { (1986) }\end{array}$ & $\begin{array}{l}\text { PHE (two } \\
\text { arrangements) }\end{array}$ & Salt pulse & Water & $5+2$ & $T$ constant \\
\hline \multirow[t]{2}{*}{$\begin{array}{l}\text { Kiesner and } \\
\quad \text { Reuter (1988) }\end{array}$} & $\begin{array}{l}\text { PHE (four } \\
\text { arrangements) }\end{array}$ & $\begin{array}{l}\text { Salt pulse, } \\
\text { nonideal }\end{array}$ & Water & 60 & $R e_{\mathrm{nm}, \mathrm{cl}}=500-8000$ \\
\hline & & & $\begin{array}{l}\text { Coffee } \\
\text { cream }\end{array}$ & & \\
\hline Burton (1958a.b) & PHE, heat & $\begin{array}{l}\text { Sodium nitrite } \\
\text { pulse }\end{array}$ & Water & 1 & $\begin{array}{c}R e=25000 \\
T=135^{\circ} \mathrm{C}\end{array}$ \\
\hline \multicolumn{6}{|l|}{ Direct HEs } \\
\hline $\begin{array}{l}\text { Cert and } \\
\text { Hermier } \\
\text { (1973) }\end{array}$ & Steam injection & Dye pulse & 一 & - & $\begin{array}{r}T=102-115^{\circ} \mathrm{C} \\
Q=1.91 / \mathrm{min}\end{array}$ \\
\hline \multirow[t]{2}{*}{ Heppell (1985) } & $\begin{array}{l}\text { Direct heating } \\
\text { and hold tube } \\
\text { of UHT plant }\end{array}$ & $\begin{array}{l}\text { Pulse of soluble } \\
\text { dye }\end{array}$ & Milk & 1 & $\begin{array}{l}R e=3500 \text { and } 10500 \\
\text { (only in holding } \\
\text { tube) }\end{array}$ \\
\hline & & & Water & 1 & $\begin{array}{c}T=138 \quad 147^{\circ} \mathrm{C}, \text { same } \\
t\end{array}$ \\
\hline \multicolumn{6}{|l|}{ SSHES } \\
\hline \multirow[t]{2}{*}{ Bateson (1971) } & $3 \mathrm{SSHE}$ & Salt pulse & $\begin{array}{l}\text { Water } \\
\text { Starch } 5 \%\end{array}$ & 11 & $(3+1+1)$ flowrates \\
\hline & & & & & $\begin{array}{l}(3+1+1) \text { rotor speeds } \\
T \text { constant }\end{array}$ \\
\hline $\begin{array}{l}\text { Chen and } \\
\text { Zahradnik } \\
(1967)\end{array}$ & $\begin{array}{l}2 \text { SSHE (one } \\
\text { heating and } \\
\text { one cooling } \\
\text { section) }\end{array}$ & $\begin{array}{l}60 \% \text { sucrose } \\
\text { pulse }\end{array}$ & Water & 12 & $\begin{array}{l}\text { each: three flowrates. } \\
\text { four rotor speeds }\end{array}$ \\
\hline $\begin{array}{l}\text { Trommelen and } \\
\text { Beek (1971) }\end{array}$ & SSHE & Dye pulse & $\begin{array}{l}\text { Glicerol } \\
\text { water } \\
\text { mixtures }\end{array}$ & 5 & $\begin{array}{l}\Delta T=20-87^{\circ} \mathrm{C} \\
\text { Same flowrate, two } \\
\text { flow regimes. four } \\
\text { rotor speeds }\end{array}$ \\
\hline $\begin{array}{l}\text { Milton and } \\
\text { Zahradnik } \\
\text { (1973) }\end{array}$ & $\begin{array}{l}2 \text { SSHE (one } \\
\text { heating and } \\
\text { one cooling } \\
\text { section) }\end{array}$ & $\begin{array}{l}60 \% \text { sucrose } \\
\text { pulse }\end{array}$ & PEG 25\% & 8 & $\begin{array}{l}\text { each: two flowrates. } \\
\text { four rotor speeds }\end{array}$ \\
\hline $\begin{array}{l}\text { Cuevas et al. } \\
(1982)\end{array}$ & Vertical SSHE & Dye step & Water & 36 & $\begin{array}{l}\wedge T=49-1>4^{\circ} \mathrm{C} \\
T=1,30^{\circ} \mathrm{C}\end{array}$ \\
\hline $\begin{array}{l}\text { Abichandani and } \\
\text { Sarma (1988) }\end{array}$ & $\begin{array}{l}\text { Horizontal thin } \\
\text { film SSHE }\end{array}$ & Salt pulse & Water & $11 \neq(32$ trials $)$ & $\begin{array}{l}\text { Three flowrates, three } \\
\text { rotor speeds, four } \\
\text { blades. } T_{\text {:mml }}\end{array}$ \\
\hline \multirow[t]{3}{*}{$\begin{array}{l}\text { Pudgiono at al. } \\
\qquad(1992)\end{array}$} & Vertical SSHE & Dye pulse & Water & 2 & $\begin{array}{l}\tau_{\text {willt }}=0 \cdot 7-9 \cdot 3 \mathrm{~s}, \text { two } \\
\text { rotor speeds }\end{array}$ \\
\hline & & & DEG & 7 & $\begin{array}{c}\tau_{1):(;}=54-82 \mathrm{~s} \\
T=20^{\circ} \mathrm{C}\end{array}$ \\
\hline & & & & & $2 Q$, five rotor speeds \\
\hline
\end{tabular}


on heating and cooling sections of aseptic processing plants (Table 12) were performed on PHEs, SSHEs and direct heating systems.

Eventual tailing effects in RTD curves should be carefully assessed. Tailing effects are masked in RTD curves obtained from a step injection of tracer. In most of the reported RTD curves obtained from a pulse injection of tracer in a holding tube, a significant tailing in RTD could be observed. Tailing effects may arise from improper injection (Milton \& Zahradnik, 1973) or indicate laminar or low turbulent flow regimes. Except for the work of Burton (1958a), negligible tailing was found for $R e$ numbers above 20000 . These effects are in general overlooked in the modelling of RTD curves.

Modelling of RTD curves in holding tubes is quite common, while only four works were found reporting modelling of RTD curves obtained in heating systems (Table 13). Models presented include (i) the velocity distribution model; (ii) the $N$ CST model, with or without PF in series; and (iii) the dispersed plug flow model. These models were based on the assumption of ideal injection of tracer, with the

TABLE 13

Models Proposed for Experimental RTD Curves

\begin{tabular}{|c|c|c|}
\hline Reference & Re/product & Model (parameters) \\
\hline \multicolumn{3}{|l|}{ Straight or hold tubes } \\
\hline Aiba and Sonoyama (1965) & $\begin{array}{l}420 / \text { water } \\
2260 / \text { water }\end{array}$ & $\begin{array}{l}\text { Velocity distribution } \\
\text { DPF }(P e=320)\end{array}$ \\
\hline \multirow{2}{*}{ Veerkamp et al. (1974) } & $860 /$ water & $\mathrm{PF}+2 \cdot 3 \mathrm{CST}$ \\
\hline & $5100 /$ water & $\mathrm{PF}+7 \mathrm{CST}$ \\
\hline Roig et al. (1976) & -/water & $\begin{array}{l}N-\operatorname{CST}(N=5) \text { and } \\
F=1-\exp \left(-a t^{\mathrm{b}}\right)\end{array}$ \\
\hline Burton et al. (1977) & - /water & PF \\
\hline \multirow{2}{*}{ Nassauer and Kessler (1979) } & $5000 /$ water & Velocity distribution \\
\hline & $5820 /$ milk & DPF+velocity distribution \\
\hline Wennerberg (1986) & $\begin{array}{l}21400 / \text { water } \\
35300 \text { water }\end{array}$ & $\begin{array}{l}N-\operatorname{CST}(N=340) \\
\operatorname{DPF}(P e=4100)\end{array}$ \\
\hline \multirow[t]{3}{*}{ Sancho and Rao (1992) } & $\begin{array}{l}800-8133 / \text { water and sucrose } \\
12 \%\end{array}$ & $N$-CST and DPF \\
\hline & $110-627 /$ guar $0 \cdot 2 \%$ & $\begin{array}{l}\left(N=14-103, P e_{\mathrm{a}}=0.02-\right. \\
0.17)\end{array}$ \\
\hline & $22-154 /$ guar $0.4 \%$ & $\begin{array}{l}\left(N=18-34, P e_{\mathrm{a}}=0.01-0.05\right) \\
\left(N=7-12, P e_{\mathrm{a}}=0.01-0.05\right)\end{array}$ \\
\hline \multicolumn{3}{|r|}{ 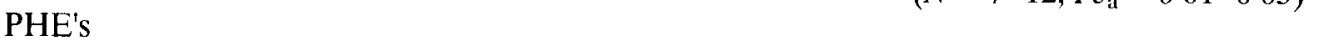 } \\
\hline Wennerberg (1986) & $\begin{array}{l}\text { (21400 and } 35300 \text { in hold)/ } \\
\text { water }\end{array}$ & 5-CST and 2 DPF \\
\hline Kiesner and Reuter (1990) & $\begin{array}{l}500-8000 / \text { water and coffee } \\
\text { cream }\end{array}$ & DPF \\
\hline \multicolumn{3}{|c|}{ Crean } \\
\hline Bateson (1971) & $\begin{array}{l}(3+1+1) \text { flowrates, } \\
(3+1+1) \text { rotor speeds/ } \\
\text { water }\end{array}$ & 'between PF and CST' \\
\hline Pudgiono et al. (1992) & $\begin{array}{l}\text { Several flowrates, and rotors } \\
\text { peeds/water and DEG }\end{array}$ & DPF \\
\hline
\end{tabular}


exception of the work of Kiesner and Reuter (1988). Model parameters were sometimes estimated by fitting the whole RTD curve to the model; alternatively, parameter estimation was based on statistical analysis, namely from the variance of RTD curves. As earlier referred, the latter procedure may lead to inaccurate estimates if tailing effects occur. In many cases curve fitting and data treatment is not very clear; the goodness of fit between experimental and predicted RTD was never quantified. Results reported by different authors for similar processing systems and conditions (Re number) are often quite different, thus making difficult to find general conclusions.

Application of RTD curves for process optimization is uncommon (PinheiroTorres \& Oliveira, 1994). RTD curves were applied to estimate final concentrations of surviving microorganisms only in a few cases (Bateson, 1971; Burton, 1958b; Burton et al., 1958, 1977; Milton \& Zahradnik, 1973; Veerkamp et al., 1974; Wennerberg, 1986).

\section{Relating mRT and RTD to processing conditions}

Some authors studied the effects of processing conditions on holding tube efficiencies: Scalzo et al. (1969) found a decrease of mRT (and thus hold tube efficiency) with product viscosity, for a number of egg products. Dickerson et al. (1968) concluded that mRT is related to tube diameter, tube length and number of bends and to the viscosity of the different milk products. Edgerton et al. (1970) studied the effect of pressure and temperature on the product maximum velocity in a hold tube. Experimental mRT values were higher than predicted values and this deviation increased with the Reynolds number. Jordan and March (1953) studied the effects of tube length, tube diameter and fluid velocity (water) on overholding time, concluding that overholding time decreases with velocity (for constant tube diameter) and increases with diameter (for constant velocity).

Analysis of the effect of processing conditions on RTD in SSHEs, was qualitatively reviewed by Singh and Lee (1992). Chen and Zahradnik (1967) and Milton and Zahradnik (1973) studied the effect of flow rate, as well as rotor speed in the latter work, on the shape of RTD curves, concluding that an increase in these parameters has a narrowing effect on RTD curves. Abichandani and Sarma (1988) confirmed these results and found that an increased number of blades would narrow the RTD.

Analysis of the effect of processing conditions in the RTD of holding tubes is scarce. Sancho and Rao (1992) found that the $P e$ number was lower for laminar than for turbulent flow, independently of the type of the liquid tested, but no clear correlation between $P e$ and $R e$ numbers could be found.

\section{CONCLUSIONS}

The knowledge of mRT is essential for sizing holding tubes. This processing time may be measured experimentally or calculated from theoretical models, that were found to yield in general conservative estimates. Experimental methods for measuring $\mathrm{mRT}$ are well described in literature and several types of tracers were proposed for different types of liquid foods. These methods should be carefully applied to provide good results. 
There is a reasonable number of published RTD studies, but there is a clear need for a systematic approach and modelling studies. RTD determinations have been mostly conducted in test rigs, at ambient temperatures and the potential of RTD for optimization studies has not been fully explored.

Several model fluids have been used for RTD studies, covering a wide range of Newtonian and pseudoplastic flow behaviour. Water has been the preferred model fluid but its applicability is quite limited when simulating real fluid foods. Fluids showing very high viscosity or yield stress have not been tested yet in spite of their evident importance in aseptic processing, e.g. for simulating some milk or egg products, sauces or purees. Furthermore, model fluids able to withstand higher temperatures (typical in aseptic processes) have not been considered yet. Studies on real food products are very limited. If RTD experiments are to be extended to these products, tracers should be carefully selected. The tracers commonly applied in real food products are in general only suitable for mRT determinations, but can be used as a start point to new developments, provided their detection methods can be improved.

Relating RTD to processing conditions in aseptic processes is quite incipient and should be developed. These studies would provide an invaluable insight in the flow behaviour as has been widely recognized in the chemical engineering field.

\section{ACKNOWLEDGEMENTS}

The first author acknowledges Junta Nacional de Investigaçcão Científica e Tecnológica (JNICT) for financial support under the scope of 'Programa Ciência' and 'Programa Praxis XXI'.

\section{REFERENCES}

Abichandani, H. \& Sarma, S. C. (1988). Residence time distribution in a horizontal thin film scraped surface heat exchanger (SSHE). Journal of Food Process Engineering, 10, 17-80.

Aiba, S. \& Sonoyama, T. (1965). Residence-time distribution of a microbial suspension in a straight pipe. Journal of Fermentation Technology, 43, 534-540.

Anonymous, (1950). Standard method for determining the holding time of HTST pasteurizers by means of the salt conductivity test. Journal of Milk and Food Technology, 13, $261-265$.

Aoust, J.-Y. d', Emmons, D. B., McKellar, R., Timbers, G. E., Todd, E. C. D., Sewell, A. M. \& Warburton, D. W. (1987). Thermal innactivation of salmonella species in fluid milk. Journal of Food Protection, 50(6), 464-501.

Aris, R. (1959). Notes on the diffusion-type model for longitudinal mixing in flow. Chemical Engineering Science, 9, 266-267.

Bailey, J. E. \& Ollis, D. F. (1986). Biochemical Engineering Fundamentals, 2nd edn, McGraw Hill, New York, Chap. 9.

Bateson, R. N. (1971). The effect of age distribution on aseptic processing. Chemical Engineering Progress Symposium Series, 108(67), 44-52.

Bird, R. B., Stewart, W. E. \& Lightfoot, E. N. (1960). Transport Phenomena, Wiley, New York. 
Bischoff, K. B. (1960). Notes on the diffusion-type model for longitudinal mixing in flow (letters to the editor). Chemical Engineering Science, 12, 69-70.

Bischoff, K. B. \& Levenspiel, O. (1962). Fluid dispersion - generalization and comparison of mathematical models - I. Generalization of models. Chemical Engineering Science, 17, 245-255.

Bischoff, K. B. \& Levenspicl, O. (1962). Fluid dispersion - generalization and comparison of mathematical models - II. Comparison of models. Chemical Engineering Science, 17. $257-264$.

Bosworth, R. C. L. (1948). Distribution of reaction times for laminar flow in cylindrical reactors. Philosophical Magazine, 39, 846-862.

Bosworth, R. C. L. (1949). Distribution of reaction times for turbulent flow in cylindrical reactors. Philosophical Magazine, 40, 314-324.

Botham, G. H. (1952). Determination of the holding time of plants pasteurizing ice cream mix. Monthly Bulletin, Ministry of Health and Public Health, 11, 82-85.

Brodkey, R. S. (1967). The Phenomena of Fluid Motions, Addison-Wesley, London.

Buffham, B. $\Lambda . \&$ Gibilaro, (1968). $\Lambda$ generalization of the tanks-in-series mixing model. AlChE Journal, 14(5), 805-806.

Burton, H. (1958). An analysis of the performance of an UHT milk sterilizing plant: I. Introduction and physical measurements. Joumal of Dairy Research, 25, 75-84.

Burton, H. (1958). An analysis of the performance of an UHT milk sterilizing plant: II. Calculation of the bactericidal effectiveness. Journal of Dairy Research, 25, 324-337.

Burton, H., Franklin, J. G., Williams, D. J., Chapman, H. R., Harrison, A. J. W. \& Clegg, L. F. L. (1958). An analysis of the performance of an UHT milk sterilizing plant: III. Comparison of experimental and calculated sporicidal effects for a strain of Bacillus subtilis. Journal of Dairy Research, 25, 338-343.

Burton, H., Perkin, A. G., Davis, F. L. \& Underwood, H. M. (1977). Thermal death kinetics of Bacillus stereathermophilus spores at ultra high temperatures. Journal of Food Technology, 12, 146-161.

Cerf, O. \& Hermier, J. (1973). Thermorésistance anormale de spores bactériennes chaufées par injection directe dans le vapeur. Lait, 521-522, 23-39.

Chen, A. C. \& Zahradnik, J. W. (1967). Residence time distributions in a SSHE. Transactions of the $A S A E, 10,508-511$.

Cuevas, R., Cheryan, M. \& Porter, V. L. (1982). Heat transfer and thermal process design in scraped-surface heat exchaners. AICHE Symposium Series, 78, 49-57.

Danckwerts, P. W. (1953). Continuous flow systems (distribution of residence times). Chemical Engineering Science, 2(1), 1-13.

Dickerson, R. W., Scalzo, A. M., Read, R. B. \& Parker, R. W. (1968). Residence time of milk products in holding tubes of high-temperature short-time pasteurizers. Joumal of Dairy Science, 51(4), 1731-1736.

Dickerson, R. W. Jr, Windau, T. D. \& Read, R. B. Jr (1974). Flow profiles in the plates of a milk pasteurizer. Joumal of Dairy Science, 57(1), 1-8.

Edgerton, E. R. \& Jones, V. A. (1970). Holding-time measurement in an ultra high temperature direct steam-injection system. Transactions of the ASAE, 13, 695-698.

Fdgerton, E. R., Iones, V. A. \& Warren, I. A. (1970). Fffect of process variables on the holding time in an ultrahigh-temperature steam injection system. Journal of Dairy Science. 53(10), 1353-1357.

Fahim, M. A. \& Wakao, N. (1982). Parameter estimation from tracer response measurements. Chemical Engineering Science, 25, 1-8.

Fogler, H. S. (1986). Elements of Chemical Reaction Engineering, Prentice Hall, New Jersey.

Fromment, G. F. \& Bischoff, K. B. (1979). Chemical Reactor Analysis and Design. Wiley, New York.

Guariguata, C., Barreiro, J. A. \& Guariguata, G. (1979). Analysis of continuous sterilization processes for Bingham plastic fluids in laminar flow. Journal of Food Science, 44, 905-910. 
Hahn, G. J. \& Shapiro, S. S. (1967). Statistical Models in Engineering, Wiley, New York, Chap. 8.

Heppell, N. J. (1985). Comparison of the residence time distributions of water and milk in an experimental UHT sterilizer. Journal of Food Engineering, 4, 71-84.

Hersom, A. C. (1985). Aseptic processing and packaging of food. Food Reviews International, $1(2), 215-270$.

Hill, C. G. (1977). An Introduction to Chemical Engineering Kinetics and Reactor Design, Wiley, New York.

Holdsworth, S. D. (1970). Continuous sterilization of foods. Process Biochemistry, 5(3), $57-62$.

Holdsworth, S. D. (1971). Applicability of rheological models to the interpretation of flow and processing behavior of fluid food products. Journal of Texture Studies, 2, 393-418.

Holdsworth, S. D. \& Richardson, P. S. (1986). Continuous sterilization operations for aseptic packaging: an overview. In Process Engineering in the Food Industry, eds Field and Howell, Elsevier, Oxford.

Hopkins, M. J., Sheppard, A. J. \& Eisenklam, P. (1969). The use of transfer functions in evaluating residence time distribution curves. Chemical Engineering Science, 24, 1131-1137.

Hubbard, D. W. \& Williams, C. N. (1977). Continuous fermenters for polysaccharide production. Process Biochemistry, 12(10), 11-13.

Janssen, P. W. M. (1994). Measurement of residence time distribution of processing plant using a cross correlation technique. Journal of Food Engineering, 21, 215-223.

Jordan, W. K. \& Holland, R. F. (1953). Studies on thermal methods for measuring the holding time in HTST pasteurizers. Joumal of Milk and Food Technology, 16(1), 15-21, 25.

Jordan, W. K. \& March, R. P. (1953). Studies on overholding in HTST pasteurizers operated on water. Journal of Dairy Science, 36(1), 614-619.

Jordan, W. K., Holland, R. F. \& White, J. C. (1949). The determination of the holding time in HTST pasteurizing units. Journal of Milk and Food Technology, 12(2), 87-92.

Kaufman, V. K., Ijichi, K. \& Putnam, G. W. (1968). Flow characteristics in holding tubes of commercial egg pasteurizers. Journal of Milk and Food Technology, 31(9), 269-273.

Kaufman, V. K., Putnam, G. W. \& Ijichi, K. (1968). Test methods for measuring minimum holding times in continuous egg pasteurizers. Journal of Milk and Food Technology, 31(10), $310-314$.

Kessler, H. G. (1989). Effect of thermal processing on milk. In Developments in Food Preservation, 3rd edn, ed. S. Thorne, Elsevier, New York, Chap. 5.

Kiesner, C. H. \& Reuter, H. (1988). Bestimmung des Verweilzeitverhaltens in Plattenwärmeaustauschern mit Hilfe des nichtidealen Impulsmethode. ChemicalEngineering-Technologie, 60(2), 142-143.

Kiesner, C. H. \& Reuter, H. (1990). Determination of residence time functions in a plate heat exchanger using nonideal tracer impulse. In Engineering and Food, eds W. E. L. Spiess \& H. Schubert, Elsevier, Oxford.

Kulozik, U., Hammelehle, B., Pfeifer, J. \& Kessler, H. G. (1992). High reaction rate continuous bioconversion process in a tubular reactor with narrow residence time distributions for the production of lactic acid. Journal of Biotecnology, 22(1/2), 107-116.

Laan, E. T. v. d. (1958). Notes on the diffusion type model for the longitudinal mixing of flow. Chemical Engineering Science, 7, 187

Law, A. M. \& Kelton, W. D. (1991). Simulation Modeling and Analysis, McGraw-Hill, New York.

Lee, J. H., Singh, R. K. \& Lineback, D. S. (1995). Particle concentration influence on liquid RTD in a model aseptic processing system. Journal of Food Process Engineering, 18(2), $119-133$.

Levenspiel, O. (1958). Longitudinal mixing of fluids flowing in circular pipes. Industrial Engineering Chemistry, 50(3), 343-346.

Levenspiel, O. (1972). Chemical Reaction Engineering (2nd edn), Wiley, New York, Chap. 9. 
Levenspiel, O. \& Bischoff, K. B. (1963). Patterns of flow in chemical process vessels. In Advances in Chemical Engineering, Vol. 4, eds T. B. Drew, J. W. Hoopes Jr \& T. Vermeulen, Academic Press, New York, pp. 95-198.

Levenspiel, O. \& Turner, J. C. R. (1970). The interpretation of residence-time experiments. Chemical Engineering Science, 25, 1605- 1609.

Levenspiel, O., Lai, B. W. \& Chatlynne, C. Y. (1970). Tracer curves and the residence time distribution. Chemical Engineering Science, 25, 611-1613.

L.cvenspiel , O. \& Smith, W. K. (1957). Diffusion-type model for longitudinal mixing in flow. Chemical Engineering Science, 6, 227-236.

Lin, S. H. (1979). Residence time distribution of flow in a continuous sterilization process. Process Biochemistry, 14(7), 23-27.

Lin, S. H. (1980). Continuous sterilization of non-newtonian liquid foods in a tubular sterilizer. Lebensmittel-Wissenschaft und Technologie, 13(3), 138-141.

Lund, D. B. (1977). Design of thermal processes for maximizing nutrient retention. Food Technology, 31(2), 71-78.

Maesmans, G., Hendrickx, M., Weng, Z., Keteleer, A. \& Tobback, P. (1992). Endpoint definition, determination and evaluation of thermal processes in food preservation. Belgian Journal of Food Chemistry and Biotechnolology, 45(5), 179

Malcata, F. X. (1991). Modeling of a series of continuous strirred tank reactors for thermal processing of liquid foods. International Joumal of Food Science and Technology, 5. $535-546$.

Milton, J. L. \& Zahradnik, J. W. (1973). Residence time distribution of a votator pilot plant using a non-newtonian fluid. Transactions of the ASAE, 16(6), 1186-1189.

Nassauer, J. \& Kessler, H. G. (1979). Zur Berechnung der Verweilzeitverteilung in einer Rohrleitung mit Armaturen. Milchwissenschaft, 34(4), 193-196.

O'Callaghan, E. \& McKenna, B. M. (1974). An improved method of measuring residence time in an ultra high temperature sterilizing plant. Transactions of the ASAE, 17, 983-986.

Østergaard, K. \& Michelsen, M. L. (1969). On the use of the imperfect tracer pulse method for determination of hold-up and axial mixing. Canadian Journal of Chemical Engineering, 47(4), 107-112.

Palmer, J. A. \& Jones, V. A. (1976). A research note: Prediction of holding times for continuous thermal processing of power-law fluids. Journal of Food Science, 41, 1233

Patel, S. S. \& Wilbey, R. A. (1990). Heat exchanger performance: the use of food colourings for estimation of minimum residence time. Joumal of the Sociery of Dairy Technology, 43(1). $25-26$.

Pethö, A. (1968). Notes on the determination of the residence time distribution in continuous-flow systems. Chemical Engineering Science, 23, 807-810.

Pinhciro-Torres, A. \& Olivcira, F. A. R. (1994). Assessing overprocessing in the ascptic processing of fluid foods: an analysis of the contribution of different portions of the fluid to average quality. In Minimal Processing of Foods and Process Optimization: an Interface. eds R. P. Singh \& F. A. R. Oliveira, CRC Press, New York.

Pudgiono, P. I., Tavare, N. S., Garside, J. \& Nigam, K. D. P. (1992). Residence time distribution from a continuous Couette flow device. Chemical Engineering Journal, 48. $101-110$.

Rangaiah. G. P. \& Krishnaswamy, P. R. (1990). Application of time domain curve-fitting to parameter estimation in RTD models. Journal of Chemical Engineering of Japan, 223(2), $124-130$.

Rao, M. A. (1973). Sizing holding tubes of HTST pasteurizers for Power law food products. Journal of Milk and Food Technology, 36(3), 181-188.

Rao, M. A. (1977). Rheology of liquid foods - a review. Journal of Texture Siudies, 8. $135-168$.

Rao, M. A. \& Loncin, M. (1974). Residence time distribution and its role in continuous pasteurization (Part I). Lebensmittel-Wissenschaft und Technologie, 7(1), 5-13. 
Rao, M. A. \& Loncin, M. (1974). Residence time distribution and its role in continuous pasteurization (Part II). Lebensmittel-Wissenschaft und Technologie, 7(1), 14-17.

Rodrigo, M., Martinez, A., Sanchis, J., Trama, J. \& Giner, V. (1990). Determination of hotfill-hold-cool process specifications for crushed tomatoes. Journal of Food Science, 55(4), $1029-1032$.

Roig, S. M., Vitali, A. A., Rodriguez, E. O. \& Rao, M. A. (1976). Residence time distribution in the holding section of a plate heat exchanger. Lebensmittel-Wissenschaft und Technologie, 9, 255-256.

Ruthven, D. M. (1971). The residence time distribution for ideal laminar flow in a helical tubc. Chemical Engineering Science, 26, 1113-1121.

Sancho, M. F. \& Rao, M. A. (1992). Residence time distribution in a holding tube. Journal of Food Engineering, 15(1), 1-19.

Sawinsky, J. \& Simandi, B. (1982). The residence time distribution for laminar flow of a nonNewtonian fluid in a straight circular tube. Transactions of the Institute of Chemical Engineering, 60, 188-190.

Scalzo, A. M., Dickerson, R. W., Read, R. B. \& Parker, R. W. (1969). Residence times of egg products in holding tubes of egg pasteurizers. Food Technology, 5(23), 80-83.

Schlichting, H. (1960). Boundary Layer Theory, McGraw-Hill, New York.

Singh, R. K. \& Lee, J. H. (1992). Residence time distributions of foods with/without particulates in aseptic processing systems. In: Advances in Aseptic Processing Technologies, eds R. K. Singh \& P. E. Nelson, Elsevier, New York, pp. 7-62.

Sjenitzer, F. (1958). How much do products mix in a pipeline?. Pipeline Engineer, December, 31-34.

Steffe, J. F. (1992). Rheological Methods in Food Process Engineering. Freeman Press, West Lansing, Michigan.

Taylor, G. (1954). The dispersion of matter in turbulent flow through a pipe. Proceedings of the Royal Society of London Series A, 223, 446-468.

Thiel, C. C. \& Burton, H. (1952). The maintenance of effective treatment in high-temperature short-time equipment for pasteurizing ice-cream mix. Monthly Bulletin of the Ministry of Health and Public Health, 11, 78-81.

Trommelen, A. M. \& Beek, W. J. (1971). Flow phenomena in a scraped-surface heat exchanger. Journal of Engineering Science, 26, 1933-1942.

Veerkamp, C. H., Romijn, A. J. M. \& Pol, J. C. (1974). Influence of varying residence time distribution on the inactivation of microorganisms during pasteurization of egg products. Lebensmittel-Wissenschaft und Technologie, 7(5), 306-310.

Watson, E. L., McKillop, A. A., Dunkley, W. L. \& Perry, R. L. (1960). Plate heat exchangersflow characteristics. Industrial Engineering Chemistry, 52(9), 733-744.

Wehner, J. F. \& Wilhelm, R. H. (1956). Boundary conditions in a flow reactor. Chemical Engineering Science, 6, 89-93.

Wen, C. Y. \& Fan, L. T. (1975). Models for Flow Systems and Chemical Reactors, Marcel Dekker, New York.

Wennerberg, J. (1986). Effects of flow distribution and variable temperature in a continuous process line. Milchwissenschaft, 41(6), 340-343.

Yeh, A.-I., Hwang, S.-J. \& Guo, J.-J. (1992). Effects of screw speed and feed rate on residence time distribution and axial mixing of wheat flour in a twin-screw extruder. Journal of Food Engineering, 17, 1-13.

Zulichem, D. J., Stewart, J. G. \& Buisman, G. (1973). Residence time distributions in an extruder. Lebensmittel-Wissenschaft und Technologie, 6(5), 184-188.

Zwietering, T. N. (1959). The degree of mixing in continuous flowing systems. Chemical Engineering Science, 11(1), 1-15. 